\title{
Molecular basis of the anti-diabetic properties of camel milk through profiling of its bioactive peptides on dipeptidyl peptidase IV (DPP-IV) and insulin receptor activity
}

\author{
Arshida Ashraf, ${ }^{1 *}$ Priti Mudgil, ${ }^{2 *}$ Abdulrasheed Palakkott, ${ }^{1} \odot$ Rabah Iratni, ${ }^{1}$ Chee-Yuen Gan, ${ }^{3} \odot$ \\ Sajid Maqsood, ${ }^{2,4}+\odot$ and Mohammed Akli Ayoub ${ }^{1,4}+$ ๑ \\ ${ }^{1}$ Department of Biology, College of Science, United Arab Emirates University, PO Box 15551, Al Ain, United Arab Emirates \\ ${ }^{2}$ Department of Food, Nutrition and Health, College of Food and Agriculture, United Arab Emirates University, PO Box 15551, Al Ain, \\ United Arab Emirates \\ ${ }^{3}$ Analytical Biochemistry Research Centre (ABrC), University of Science, Malaysia, 11800 USM, Penang, Malaysia \\ ${ }^{4}$ Zayed Center for Health Sciences, United Arab Emirates University, PO Box 15551, Al Ain, United Arab Emirates
}

\section{ABSTRACT}

The molecular basis of the anti-diabetic properties of camel milk reported in many studies and the exact active agent are still elusive. Recent studies have reported effects of camel whey proteins (CWP) and their hydrolysates $(\mathrm{CWPH})$ on the activities of dipeptidyl peptidase IV (DPP-IV) and the human insulin receptor (hIR). In this study, CWPH were generated, screened for DPP-IV binding in silico and inhibitory activity in vitro, and processed for peptide identification. Furthermore, pharmacological action of intact CWP and their selected hydrolysates on hIR activity and signaling and on glucose uptake were investigated in cell lines. Results showed inhibition of DPP-IV by CWP and CWPH and their positive action on hIR activation and glucose uptake. Interestingly, the combination of CWP or CWPH with insulin revealed a positive allosteric modulation of hIR that was drastically reduced by the competitive hIR antagonist. Our data reveal for the first time the profiling and pharmacological actions of CWP and their derived peptides fractions on hIR and their pathways involved in glucose homeostasis. This sheds more light on the anti-diabetic properties of camel milk by providing the molecular basis for the potential use of camel milk in the management of diabetes.

Key words: diabetes, camel milk, insulin receptor, DPP-IV

Received April 1, 2020.

Accepted August 18, 2020.

*These authors equally contributed to this work.

†Corresponding authors: sajid.m@uaeu.ac.ae and mayoub@uaeu.ac

\section{INTRODUCTION}

Camel milk is a popular commodity used in many parts of the world, particularly in arid and semi-arid zones. Camel milk's therapeutic properties against diseases such as diabetes and cancer have been widely studied and reviewed in the past decade (Alavi et al., 2017; Ayoub et al., 2018). It is also widely noted that camel milk consumption is beneficial in reducing the dose of insulin needed to induce glycemic control and improves fasting blood glucose (Agrawal et al., 2005, 2011; Mohamad et al., 2009). Hence, a growing worldwide trend is emerging, related to camel milk consumption for management of diabetes (Malik et al., 2012; Agrawal et al., 2013). Despite the presence of traditional and fundamental scientific information related to the anti-diabetic properties of camel milk, the exact mechanism of its action remains unclear and warrants further investigation. Moreover, the exact hypoglycemic agent contained in camel milk has not yet been identified, and its molecular mechanisms at the tissue and cellular levels have not been investigated. Thus, it is not clear whether the anti-diabetic effects of camel milk can be attributed to only one specific component acting on one specific target or, rather, are the result of the harmonious actions of multiple components on different tissue sites in the body (Ayoub et al., 2018).

One anticipated mechanism of the anti-diabetic action of camel milk might be attributable to the inhibition of various metabolic enzymes related to the progression of diabetes, such as dipeptidyl peptidase IV [DPP-IV, an enzyme that degrades the insulin-secreting incretin hormones glucagon-like peptide (GLP) and gastric inhibitory polypeptide (GIP)], $\alpha$-amylase, and $\alpha$-glucosidase (Mudgil et al., 2018). Recent reports on the potent inhibition of DPP-IV, via bioactive peptides obtained after hydrolysis of camel milk proteins, has garnered scientific interest in the elucidation of their molecular mechanism of action (Kamal et al., 2018; Mudgil et 
al., 2018). The potential of whey protein from camel milk remains underreported (Jafar et al., 2018; Mudgil et al., 2019a; Nongonierma et al., 2019). Until now, very few reports have explored camel whey-generated hydrolysates for their anti-diabetic properties. Camel whey proteins are known to possess greater numbers of biologically active proteins than their bovine counterparts (Mati et al., 2017). Camel whey contains several other immunomodulatory proteins, such as lactoferrin, serum albumin, $\alpha$-lactalbumin, lactophorin, and peptidoglycan, which are naturally present and are part of the primary sequence of whey proteins (El-Hatmi et al., 2007). These proteins can significantly contribute to the release of bioactive peptide sequences during digestion in the gut and can also be produced by in vitro enzymatic hydrolysis (Gauthier et al., 2006). Noticeably, $\alpha$-lactalbumin from camel whey protein is reported to possess several motifs of Trp-containing dipeptides that can produce potent DPP-IV inhibitory peptides. Significant differences in whey proteins in camel milk compared with those of bovine milk, and their roles in anti-diabetic effects, prompted us to further investigate the molecular pathway responsible for anti-diabetic effects of camel whey proteins (CWP) and their pepsin-derived hydrolysates (CWPH). The present study represents one of few reports providing further scientific findings on whey protein hydrolysates with potential anti-diabetic activity.

Furthermore, insulin and its action on human insulin receptor (hIR) plays a key role in glucose homeostasis and the etiology of diabetes. Studies have speculated on the presence of insulin as well as insulin-like proteins or peptides in camel milk, but the real picture of this is still not clear (Ayoub et al., 2018). Along this line, a recent in vitro study reported a pharmacological action of raw camel milk proteins on hIR transiently expressed in human embryonic kidney 293 (HEK293) cells by increasing insulin efficacy, suggesting an allosteric mode of action (Abdulrahman et al., 2016). That study was the first to provide the rationale and a molecular basis of the hypoglycemic properties of camel milk. All these aspects were addressed in our recent review (Ayoub et al., 2018) and constitute the rationale behind our hypothesis that the hypoglycemic properties of camel milk may involve a pharmacological action of its protein and peptide fractions on hIR and its downstream signaling pathways in the major insulin-sensitive tissues. Thus, in the present study we first aimed to profile CWP and their hydrolysates for their DPP-IV inhibitory properties. Selected hydrolysates were sequenced for peptide identification by liquid chromatography-mass spectrometry quadrupole time of flight analysis, and in silico molecular docking of the identified peptides with DPP-
IV enzyme was carried out. Next, the pharmacological effects of CWP and their hydrolysates on hIR function and its major downstream signaling were explored. For this, HEK293 transiently expressing hIR were applied to assess the activation of hIR using bioluminescence resonance energy transfer (BRET), which measures the physical translocation of insulin receptor substrate 1 (IRS1) in intact cells to the activated receptor upon challenge with different camel milk peptide fractions. In addition, the phosphorylation status of hIR and the key kinases of its downstream signaling pathway, Akt and extracellular signal-regulated kinases 1 and 2 (ERK1/2), were investigated in both transfected HEK293 cells and human hepatocellular carcinoma (HepG2) cells endogenously expressing hIR. Finally, we attempted to link our data on the molecular pathway with a more integrated cell response by assessing glucose uptake in HepG2 in response to the different camel milk fractions.

\section{EXPERIMENTAL SECTION}

\section{Chemicals and Reagents}

Human insulin, pepsin from porcine gastric mucosa (EC 232-629-3), human DPP-IV, Gly-pro-p-nitroanilide, and most of the solvents used for chromatographic studies were purchased from Sigma Aldrich (St. Louis, $\mathrm{MO}$ ). The mammalian expression plasmids used for the transient expression in HEK293 cells and coding for hIR-Rluc and its signaling protein substrate, IRS1yellow fluorescent protein (YFP), were generously provided by Dr. Tarik Issad (Cochin Institute, Paris, France). Fresh raw camel milk was supplied by local camel farmers at Al Ain, United Arab Emirates (UAE). The milk samples were collected in the early morning and, after labeling, were immediately transported to the United Arab Emirates University laboratories (Al Ain) under refrigerated conditions $\left(4^{\circ} \mathrm{C}\right)$. The hIR, Akt, and ERK1/2 antibodies (against native and phosphorylated forms) were purchased from Cell Signaling Technology (Boston, MA). The glucose uptake kit was purchased from Promega Corp. (Madison, WI), and the S961 peptide was a gift from Dr. Lauge Schäffer (Novo Nordisk, Copenhagen, Denmark).

\section{Preparation of Camel Whey and Production of CWPH}

To obtain CWP, the acid precipitation method was employed, followed by centrifugation (Jafar et al., 2018). Various raw camel milk samples were obtained from healthy camels of the same breed (Camelus dromedarius), which were reared at local camel farms in 
$\mathrm{Al}$ Ain, UAE. Milk samples were pooled to obtain a composite sample and immediately transferred to the laboratory under ice storage conditions.

Camel milk was skimmed twice by centrifugation at $4,255 \times g, 20 \mathrm{~min}$ at $10^{\circ} \mathrm{C}$. The skimmed camel milk was then subjected to acid precipitation until $\mathrm{pH} 4.0$ was reached, by addition of $1 \mathrm{~N} \mathrm{HCl}$, and milk samples were allowed to settle for $1 \mathrm{~h}$ followed by centrifugation thrice at $10,000 \times g, 10 \mathrm{~min}$ at $4^{\circ} \mathrm{C}$, to separate the whey from casein fractions. This step was repeated 2 times to separate whey from casein efficiently. Whey samples were then frozen at $-20^{\circ} \mathrm{C}$ and freeze-dried using a LyoAlfa freeze dryer (Telstar, Terrassa, Spain) to obtain a camel whey powder. The whey powder was reconstituted in deionized water to a protein content of $3.0 \%$ (wt/vol) using bicinchoninic acid protein assay. The $\mathrm{pH}$ was adjusted to the optimum value for pepsin enzyme ( $\mathrm{pH} 2.0)$. The samples were then divided into 3 batches and hydrolyzed separately, with addition of a defined amount of pepsin to obtain a desired enzyme-to-substrate $(\mathbf{E}: \mathbf{S})$ ratio $(2$, 1 , and $0.5 \%$ ). These fractions were then hydrolyzed at 2 different temperatures, 30 and $37^{\circ} \mathrm{C}$, in a water bath under constant agitation. The samples were incubated for 2 and $6 \mathrm{~h}$ of hydrolysis time, and thereafter the enzymes were heat-deactivated at $100^{\circ} \mathrm{C}$ for $10 \mathrm{~min}$ and centrifuged at $10,000 \times \mathrm{g}, 15 \mathrm{~min}$ at $4^{\circ} \mathrm{C}$, and the supernatants were collected and stored at $-20^{\circ} \mathrm{C}$ for further analysis. Overall, 12 hydrolysates were generated, and 1 control sample without addition of enzyme was prepared (Table 1).

\section{Extent of Hydrolysis Determination}

The extent of hydrolysis via determination of free amino group content (AN) among the camel whey protein hydrolysates $(\mathbf{H 1}-\mathbf{H 1 2})$ was determined using the O-phthaldialdehyde method as previously described (Church et al., 1983) and modified (Mudgil et al., 2019b). Absorbance values at $340 \mathrm{~nm}$ were measured with a microplate reader (Multiskan Sky, Thermo Fisher Scientific, Waltham, MA). The AN was calculated using Equation [1], as previously described (Nongonierma et al., 2019):

$$
\mathrm{AN}=\mathrm{AN}_{2}-\mathrm{AN}_{1}
$$

where $\mathrm{AN}_{1}$ and $\mathrm{AN}_{2}$ are the free amino group contents of the camel whey before and after hydrolysis, respectively. Degree of hydrolysis was performed on each batch of hydrolysates in triplicate.

\section{Peptide Profile of CWPH Through Reverse-Phase Ultra Performance Liquid Chromatography}

Peptide profiles of CWP and selected CWPH (H3, H5, H11, and H12) were analyzed via reverse-phase ultra performance liquid chromatography (Thermo Fisher Scientific) following the method previously described, with some modifications (Nongonierma and FitzGerald, 2012). For a detailed description of the method, please refer to the supplemental materials, section S1.1 (https://doi.org/10.3168/jds.2020-18627).

Table 1. Description of design of experiment (temperature, enzyme-to-substrate ratio, and time) used to produce camel whey protein hydrolysates, their degree of hydrolysis, and their inhibitory concentration values for dipeptidyl peptidase IV inhibition ${ }^{1}$

\begin{tabular}{lccccc}
\hline \multicolumn{3}{c}{ Variable levels } & & \\
\cline { 2 - 3 } Hydrolysate & $\begin{array}{c}\text { Temperature } \\
\left({ }^{\circ} \mathrm{C}\right)\end{array}$ & $\begin{array}{c}\text { E:S } \\
(\%)\end{array}$ & $\begin{array}{c}\text { Time } \\
(\text { min })\end{array}$ & $\begin{array}{c}\text { AN } \\
(\mu \mathrm{g} \text { of NH} / g)\end{array}$ & $\begin{array}{c}\text { IC } \\
\text { inhibition }(\mathrm{mg} / \mathrm{mL})\end{array}$ \\
\hline CWP & 37 & 0 & 360 & & $8.46 \pm 0.053^{\mathrm{a}}$ \\
H1 & 30 & 2.0 & 120 & $341.8 \pm 5.1^{\mathrm{d}}$ & $0.73 \pm 0.003^{\mathrm{d}}$ \\
H2 & 30 & 2.0 & 360 & $276.6 \pm 31.7^{\mathrm{c}}$ & $0.44 \pm 0.002^{\mathrm{d}}$ \\
H3 & 30 & 1.0 & 120 & $131.8 \pm 34.4^{\mathrm{a}}$ & $0.44 \pm 0.014^{\mathrm{d}}$ \\
H4 & 30 & 1.0 & 360 & $204.7 \pm 7.1^{\mathrm{b}}$ & $0.46 \pm 0.013^{\mathrm{d}}$ \\
H5 & 30 & 0.5 & 120 & $211.6 \pm 5.3^{\mathrm{b}}$ & $8.26 \pm 0.424^{\mathrm{a}}$ \\
H6 & 30 & 0.5 & 360 & $414.1 \pm 8.4^{\mathrm{e}}$ & $0.92 \pm 0.005^{\mathrm{d}}$ \\
H7 & 37 & 2.0 & 120 & $293.3 \pm 2.3^{\mathrm{c}}$ & $5.02 \pm 0.003^{\mathrm{b}}$ \\
H8 & 37 & 2.0 & 360 & $382.2 \pm 27.1^{\mathrm{de}}$ & $0.94 \pm 0.004^{\mathrm{d}}$ \\
H9 & 37 & 1.0 & 120 & $219.8 \pm 2.0^{\mathrm{b}}$ & $0.59 \pm 0.003^{\mathrm{d}}$ \\
H10 & 37 & 1.0 & 360 & $273.6 \pm 20.3^{\mathrm{c}}$ & $0.85 \pm 0.038^{\mathrm{d}}$ \\
H11 & 37 & 0.5 & 120 & $188.6 \pm 12.9^{\mathrm{b}}$ & $0.74 \pm 0.035^{\mathrm{d}}$ \\
H12 & 37 & 0.5 & 360 & $198.9 \pm 10.5^{\mathrm{b}}$ & $2.24 \pm 0.003^{\mathrm{c}}$ \\
\hline
\end{tabular}

${ }^{\mathrm{a} e}$ Within the same column, values with different superscript letters are significantly different $(P<0.05)$.

${ }^{1}$ Data presented as mean $\pm \mathrm{SD}(\mathrm{n}=3)$. DPP-IV = dipeptidyl peptidase IV; CWP = camel whey protein; E:S $=$ enzyme-to-substrate ratio; $\mathrm{AN}=$ free amino group content; $\mathrm{IC}_{50}=$ concentration inducing $50 \% \mathrm{DPP}-\mathrm{IV}$ inhibition, expressed in $\mathrm{mg}$ of protein equivalent per $\mathrm{mL}$. 


\section{DPP-IV Inhibition Assay}

The DPP-IV inhibition assay was performed in triplicate $(\mathrm{n}=3)$ as earlier described (Mudgil et al., 2018). Values of the concentration that inhibits $50 \%$ of DPP-IV activity $\left(\mathbf{I C}_{50}\right)$ were determined by plotting the percentage inhibition as a function of the test compound concentration. For a detailed description of the method, please refer to Supplemental File S1, section S1.2 (https://doi.org/10.3168/jds.2020-18627).

\section{Identification of DPP-IV Inhibitory Bioactive Peptides Among Different Hydrolysates Using Liquid Chromatography-Mass Spectrometry Quadrupole Time of Flight, and In Silico Analysis of Peptides Identified}

Peptide sequencing for selected CWPH (H3, H5, H11, and H12) was conducted using Agilent liquid chromatography-mass spectrometry quadrupole time of flight (Agilent Technologies, Santa Clara, CA), as previously described by Sarah et al. (2016). These hydrolysates were selected for peptide identification based on a range (low, medium, and high inhibition) of DPPIV $\mathrm{IC}_{50}$ values, to understand the variations in their peptide profiles, if any, among these hydrolysates.

The list of peptides obtained were subsequently screened using the Peptide Ranker web server (http: //distilldeep.ucd.ie/PeptideRanker/). Peptides with scores above 0.80 were designated as potentially bioactive peptides (BAP) and subjected to novelty check using existing database search software (BIOPEP, PeptideDB, SwePep, and EROP-Moscow; Minkiewicz et al., 2008; Liu et al., 2008). BIOPEP and SWePep were assessed at http://www.uwm.edu.pl/biochemia and http://www.peptides.be, respectively. These databases contain all the reported BAP sequences being identified in proteins from various sources. Please refer to Supplemental File S1, section S1.3 (https://doi.org/ 10.3168/jds.2020-18627) for detailed descriptions of the method applied and the binding mechanisms of the selected peptides against DPP-IV via in silico approach.

\section{Cell Culture and Transfection}

We maintained HepG2 and HEK293 cells at $37^{\circ} \mathrm{C}$, $5 \% \mathrm{CO}_{2}$, in complete RPMI and Dulbecco's modified Eagle's medium (DMEM), respectively, containing phenol red, $4.5 \mathrm{~g} / \mathrm{L}$ glucose, $0.3 \mathrm{mg} / \mathrm{mL}$ glutamine, 100 $\mathrm{IU} / \mathrm{mL}$ penicillin, and $100 \mu \mathrm{g} / \mathrm{mL}$ streptomycin, and supplemented with $10 \%$ fetal calf serum (Gibco, Carlsbad, CA). Transient transfections in HEK293 cells were carried out in both 96-well and 6-well plates using Lipofectamine 2000 (Invitrogen, Carlsbad, CA) and $50 \mathrm{ng}$ (for 96-well plates) or $1 \mu \mathrm{g}$ (for 6 -well plates) per well of hIR-Rluc (BRET donor) with $100 \mathrm{ng}$ (for 96-well plates) or $1 \mu \mathrm{g}$ (for 6-well plates) per well of IRS1-YFP (BRET acceptor), as previously described (Abdulrahman et al., 2016). For phosphorylation experiments, only hIR-Rluc was expressed in 6-well plates. All assays were carried out $48 \mathrm{~h}$ post-transfection.

\section{Akt and ERK1/2 Phosphorylation Assays}

The HepG2 cells and HEK293 cells endogenously and transiently expressing hIR, respectively, were seeded onto 6 -well plates at $10^{6}$ cells/well, treated as indicated in figure legends, and the phosphorylation statuses of hIR, Akt, and ERK1/2 were analyzed using the following antibodies: mouse monoclonal anti-phospho-insulin receptor (pIR-Tyr1334, Thermo Fisher Scientific; 1:1,000 dilution), mouse monoclonal anti-phospho-Akt (pAkt-S473, Cell Signaling Technology; 1:2,000 dilution), and mouse anti-phospho-p44/42 (pERK1/2, Cell Signaling Technology; 1:2,000 dilution), as previously described (Ali et al., 2019). Densitometry analysis of membrane was performed using Image Studio Version 5.2 software (LI-COR, Lincoln, NE).

\section{BRET Assay}

We used BRET technology as previously described for hIR-IRS1 interaction (Abdulrahman et al., 2016). Cells coexpressing hIR-Rluc and IRS1-YFP were first seeded in 96-well white plates, washed with $50 \mu \mathrm{L} /$ well of PBS, and treated for $60 \mathrm{~min}$ at $37^{\circ} \mathrm{C}$ with 40 $\mu \mathrm{L}$ of PBS ( $\mathrm{pH}$ 7.4: $137 \mathrm{mM} \mathrm{NaCl}, 2.7 \mathrm{mM} \mathrm{KCl}, 8$ $\mathrm{m} M \mathrm{Na} 2 \mathrm{HPO} 4$, and $2 \mathrm{~m} M \mathrm{KH} 2 \mathrm{PO} 4$ ) containing or not containing (control) the indicated doses of insulin, the different camel milk fractions, or the combination of both. Following treatment, $10 \mu \mathrm{L}$ of coelenterazine $\mathrm{h}$ (Promega) was added to a final concentration of $5 \mu M$, and BRET measurements were carried out using the Tristar 2 multilabel plate reader (Berthold, Germany).

\section{Glucose Uptake Assay}

Glucose uptake in HepG2 cells was carried out using Glucose Uptake-Glo Assay (Promega). For this, HepG2 cells seeded in a 96-well white plate $(50,000$ cells/well) were first washed with PBS and starved in phenol red-, glucose-, and serum-free medium (DMEM containing $0.01 \mathrm{~m} M$ HEPES, $0.3 \mathrm{mg} / \mathrm{mL}$ glutamine, $100 \mathrm{IU} / \mathrm{mL}$ penicillin, and $100 \mu \mathrm{g} / \mathrm{mL}$ streptomycin). Then, cells were first treated or not with either insulin or camel milk fractions, as indicated, for $60 \mathrm{~min}$ at $37^{\circ} \mathrm{C}$. The treatment was removed, and the cells were washed once with PBS and then incubated with 50 
$\mu \mathrm{L} /$ well of freshly prepared 2-deoxyglucose $(500 \mu M)$ for $10 \mathrm{~min}$ at room temperature. The uptake process was stopped and neutralized, followed by addition of $50 \mu \mathrm{L} /$ well of 2-deoxyglucose-6-phosphate (2DG6P) detection reagent and incubation for 15 to $60 \mathrm{~min}$ at room temperature. Glucose-6-phosphate dehydrogenase (G6PDH) oxidizes 2DG6P to 6-phosphodeoxygluconate (6PDG) and reduces NADP + to NADPH. The reductase uses NADPH to convert proluciferin to luciferin, which is then used by Ultra-Glo recombinant luciferase (Promega, Madison, WI) to produce luminescence. This luminescence which is proportional to the amount of 2-deoxyglucose transported inside the cells upon treatment was then measured using a 0.3- to 1-s integration on GloMax Discover luminometer according to Glucose Uptake-Glo protocol (Promega).

\section{Data Presentation and Statistical Analysis}

All the pepsin-derived CWPH were produced in 3 batches, and degree of hydrolysis (AN values) and DPP-IV inhibitory activity were measured in triplicate. For DPP-IV and AN values, the data were subjected to ANOVA, and appropriate means separation was conducted using Tukey's multiple range test, using a statistical software program (SPSS v. 21 for Windows, 2012; IBM Corp., Armonk, NY). For BRET, the data were first converted to ligand-induced BRET signals by subtracting the ratios obtained from vehicle-treated cells from the same ratio obtained from cells treated with either insulin, AngII, or camel milk fractions. Then, the data were normalized by taking as $100 \%$ the maximal insulin- or AngII-induced BRET signal in the control (absence of any treatment with camel milk fractions). All data were analyzed and fitted using GraphPad Prism software (GraphPad Software Inc., La Jolla, CA). Statistical analyses for BRET and phosphorylation data were performed with 2-way ANOVA with multiple comparison test, using Bonferroni and Sidak tests to determine statistical significance between the different treatments and conditions as indicated in figure legends: ${ }^{* * * *} P<0.0001,{ }^{* * *} P<0.001,{ }^{* *} P<$ $0.01,{ }^{*} P<0.05$, and ns (nonsignificant) $P>0.05$.

\section{RESULTS}

\section{Free Amino Nitrogen Content of CWPH}

Results suggested that free amino content (AN) of 12 hydrolysates produced through pepsin hydrolysis with the current experimental design varied between 131.8 and $414.1 \mu \mathrm{g}$ of $\mathrm{NH}_{3} / \mathrm{mL}$ for $\mathrm{H} 3$ and $\mathrm{H} 6$, respectively (Table 1). Significant differences $(P<0.05)$ were seen for the AN content when the time of hydrolysis was increased from 120 to $480 \mathrm{~min}$ for all the hydrolysates. At $37^{\circ} \mathrm{C}$, reported to be an optimum temperature for pepsin, AN content of the hydrolysates showed an increasing trend, with increase in enzyme concentration from 0.5 to $2 \%$ as well as increase in time of hydrolysis from 120 to $480 \mathrm{~min}$.

\section{Peptide Profile by Reverse-Phase Ultra Performance Liquid Chromatography}

Peptide profiles of intact CWP and their selected hydrolysates (H3, H5, H11, and H12) were also characterized using reverse-phase ultra performance liquid chromatography (Figure 1). As indicated, the intact CWP possessed an intact peak of $\alpha$-lactalbumin eluted between 83 and $85 \mathrm{~min}$ and some minor whey proteins eluted between 68 to $78 \mathrm{~min}$. Upon hydrolysis, $\alpha$-lactalbumin underwent almost complete degradation, with no intact peak for $\alpha$-lactalbumin being detected (Figure 1). All 4 hydrolysates displayed elution of peptide peaks mainly toward lower retention time, ranging from 35 to $70 \mathrm{~min}$, indicating generation of peptides with wide ranges of hydrophobicity and molecular weights (Figure 1). The results also correspond well with the levels of AN values obtained, indicating generation of smaller peptides with progression of time of hydrolysis.

\section{Inhibition of DPP-IV Activity by CWPH}

The DPP-IV inhibitory properties of CWPH, expressed as DPP-IV $\mathrm{IC}_{50}(\mathrm{mg}$ of protein equivalent $/ \mathrm{mL}$ ) are presented in Table 1. Overall, it was observed that DPP-IV-IC ${ }_{50}$ values for all CWPH were significantly $(P$ $<0.05)$ lower, compared with intact whey protein, at all conditions used for hydrolysate generation. Similar findings were reported by Kamal et al. (2018), who found that hydrolysis of CWP with different enzymes (pepsin, trypsin, and chymotrypsin) enhanced DPP-IV inhibition activity 3 - to 4-fold compared with unhydrolyzed whey proteins $(P<0.05)$. The hydrolysates $\mathrm{H} 2$ and $\mathrm{H} 3$ exhibited the highest inhibitory activity with the lowest $\mathrm{IC}_{50}$ value $(0.44 \mathrm{mg} / \mathrm{mL})$, and $\mathrm{H} 5(8.26 \mathrm{mg} /$ $\mathrm{mL}$ ) possessed the weakest inhibition of DPP-IV, with an $\mathrm{IC}_{50}$ value very close to unhydrolyzed whey proteins $(8.46 \mathrm{mg} / \mathrm{mL})$. Overall, it was observed that pepsin hydrolysis carried out at $30^{\circ} \mathrm{C}$ during the first $120 \mathrm{~min}$ of hydrolysis produced hydrolysates that displayed the highest DPP-IV inhibitory activity when expressed at $1 \% \mathrm{E}: \mathrm{S}$ concentration, whereas the activity was lowest when expressed at $0.5 \% \mathrm{E}: \mathrm{S}(P<0.05$; Table 1$)$.

Hydrolysates H3, H5, H11, and H12, demonstrating a range of DPP-IV $\mathrm{IC}_{50}$ values, were selected and further subjected to identification of the peptide sequence. 


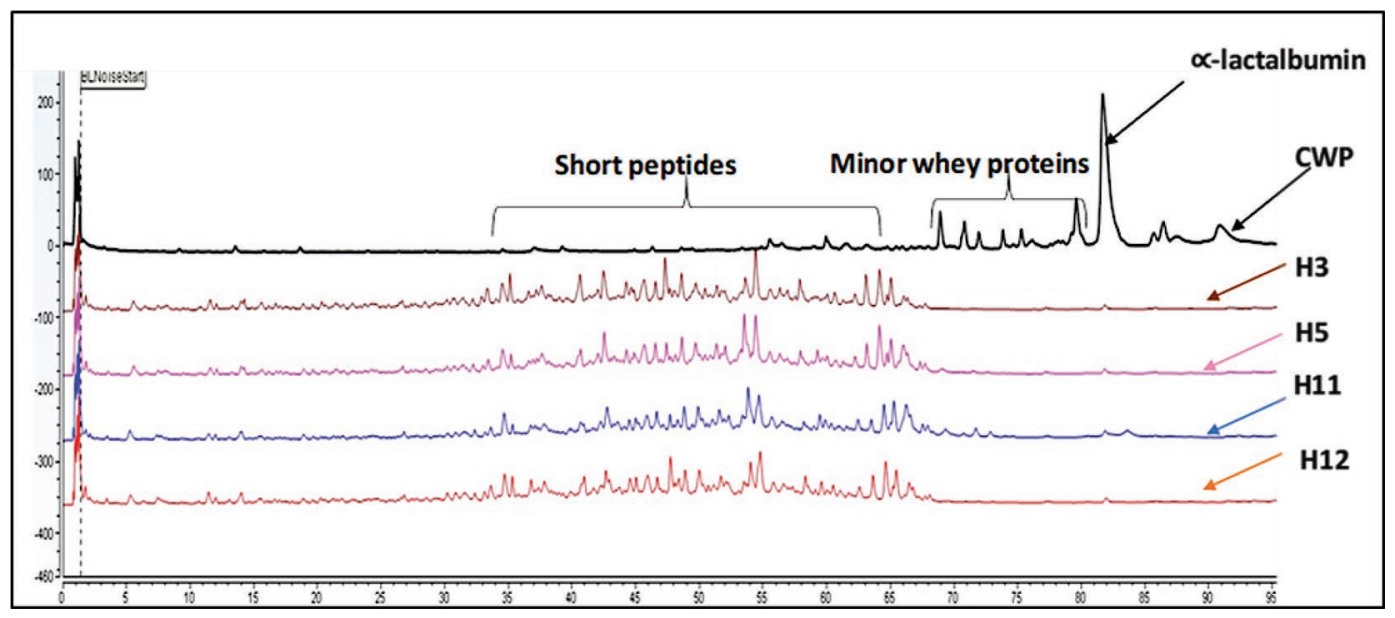

Figure 1. Reverse-phase ultra performance liquid chromatography peptide profile of intact camel whey proteins (CWP) and selected hydrolysates (H3, H5, H11, and H12).

Overall, 43, 48, 44, and 48 peptides were identified in hydrolysates $\mathrm{H} 3, \mathrm{H} 5, \mathrm{H} 11$, and $\mathrm{H} 12$, respectively (Supplemental Table S1, https://doi.org/10.3168/ jds.2020-18627). Identified peptides were classified as
BAP based on an average local confidence value of at least $80 \%$ and Peptide Ranker score of $>0.80$. A complete list of peptides having a Peptide Ranker score of $>0.80$ are displayed in Table 2 . A total of $3,4,4$, and

Table 2. Identified bioactive peptides in selected camel whey protein hydrolysate samples (H3, H5, H11, and H12) and their potential binding sites with dipeptidyl peptidase IV (DPP-IV) enzymes

\begin{tabular}{|c|c|c|c|c|c|}
\hline Sample & Peptide & $\begin{array}{l}\text { Peptide Ranker } \\
\text { score }^{1}\end{array}$ & $\begin{array}{l}\text { Pepsite } 2 \\
(P \text {-value })^{2}\end{array}$ & $\begin{array}{l}\text { Reactive residue } \\
\text { in peptide }\end{array}$ & Bound residues of DPP-IV \\
\hline \multirow[t]{4}{*}{$\mathrm{H} 3$} & CCGM & 0.96 & 0.01683 & Cys-2, Gly-3, Met- 4 & Tyr48, Trp627, Trp629, ${ }^{*}$ His748, Tyr752 \\
\hline & PAGNFLM $\dagger$ & 0.85 & 0.01628 & Pro-1, Phe-5, Leu-6, Met-7 & $\begin{array}{l}\text { Phe } 357,{ }^{*} \text { Tyr547, }{ }^{*} \operatorname{Trp} 629, * \text { Ser630, }{ }^{* *} \text { Tyr631, } \\
\text { Val656, Trp662, Tyr666, }{ }^{*} \text { Tyr752 }\end{array}$ \\
\hline & NGLMHR $\dagger$ & & 0.182 & Asn-1, Gly-2, Leu-3 & Tyr48, Trp627, Trp629, ${ }^{*}$ His748, Tyr752 \\
\hline & MFE & 0.80 & 0.05819 & Met-1, Phe-2 & Trp627, Trp629, * Tyr752 \\
\hline \multirow[t]{3}{*}{ H5 } & $\mathrm{FM}$ & 1.00 & 0.000383 & Phe-1, Met-2 & Trp627, Trp629, ${ }^{*}$ Tyr752 \\
\hline & YDFL & 0.87 & 0.1242 & Tyr-1, Phe-3, Leu-4 & $\begin{array}{l}\text { Phe357,* Tyr547,* Pro550, Cys551, Tyr585,* } \\
\text { Tyr666,* Tyr670 }\end{array}$ \\
\hline & LP & 0.80 & $1.76 \mathrm{E}-05$ & Leu-1, Pro-2 & Tyr48, Trp627, Trp629, ${ }^{*}$ His748, Tyr752 \\
\hline \multirow[t]{2}{*}{ H11 } & LRPFL & 0.93 & 0.008122 & Arg-2, Pro-3, Phe- 4 & Tyr48, Trp627, Trp629,* His740,** Gly741, Tyr752 \\
\hline & LRFPL & 0.91 & 0.008122 & Arg-2, Phe-3, Pro-4 & Tyr48, Trp627, Trp629, ${ }^{*}$ His740, ${ }^{* *}$ Gly741, Tyr752 \\
\hline \multirow{4}{*}{ H12 } & PVAAAPVM $\dagger$ & & 0.0783 & Pro-1, Pro-6, Val-7 & $\begin{array}{l}\text { Tyr48, Tyr547,* Trp } 629, * \text { Tyr631,* Tyr666,* } \\
\text { Gly741, His748, Tyr752 }\end{array}$ \\
\hline & FCCLGPVPP & 0.84 & 0.009631 & Cys-2, Cys-3, Pro-8, Pro-9 & Tyr48, Phe357,* Tyr547,* Pro550, Trp627, Trp629* \\
\hline & MLPLML $\dagger$ & 0.80 & 0.05484 & Met-1, Leu-2, Pro-3 & $\begin{array}{l}\text { Phe357, }{ }^{*} \text { Tyr } 547, * \text { Pro550, Ser630,** Tyr631,* } \\
\text { Val656, Trp659, Tyr662,* Tyr666, }{ }^{*} \text { Tyr670 }\end{array}$ \\
\hline & PFTMGY $\dagger$ & & 0.2855 & Phe-2, Thr-3, Tyr-6 & Phe357, ${ }^{*}$ Tyr547, ${ }^{*} \operatorname{Trp} 627, \operatorname{Trp} 629,{ }^{*} \operatorname{Tyr} 752$ \\
\hline
\end{tabular}

${ }^{1}$ http://distilldeep.ucd.ie/PeptideRanker/.

${ }^{2}$ http://pepsite2.russellab.org.

*Binding site for known DPP-IV commercial inhibitors; ** part of catalytic triad of active site of DPP-IV.

$\dagger$ Most efficient binding peptides. 
4 peptides, respectively, were qualified (Peptide Ranker score $>0.8)$ to be BAP in hydrolysates H3, H5, H11, and H12 (Table 2).

\section{DPP-IV Inhibitory Peptide Identifications and Molecular Interactions In Silico}

To determine the potential interactions of camel whey protein-derived BAP with DPP-IV enzyme, a computational prediction software, Pepsite2 (http:/ /pepsite2.russellab.org), was used. Table 2 shows the Peptide Ranker scores, $P$-values, and potential binding sites of the identified peptides in hydrolysates H3, H5, H11, and H12 with DPP-IV.

In the present study, all the identified peptides in hydrolysates H3, H5, H11, and H12 were capable of binding with at least 1 key residue in the active site of DPP-IV (Table 2). In particular, PAGNFLM from H3 and MLPLML from H12 could bind up to 9 important sites and remain the only peptides that could bind to Ser630 of the catalytic triad. In addition, MLPLML can also bind to Val656 and Trp659, which are the same amino acids bound by the commercial inhibitor saxagliptin. We further found that PAVACCL (H12), PPLPCHM, and YDFL (H5), and PAGNFLP and PVAAAPVM (H12), could bind to 5 and 4 important active site residues from DPP-IV. Moreover, LRPFL, LRFPL, and HSGF from H11 could bind to His740 of the catalytic triad, indicating their potential to inhibit DPP-IV activity. Therefore, these peptides are proposed to be the potential DPP-IV inhibitors.

\section{Positive Effects of CWP on hIR Activity in Intact HEK293 Cells}

As stated, we hypothesized that the hypoglycemic properties of camel milk may involve a pharmacological action of its protein or peptide components on hIR and its downstream signaling pathways in the major insulin-sensitive tissues. Therefore, we examined the putative effects of raw CWP and its hydrolysates on the activation of hIR transiently expressed in HEK293 cells. For this, we first used BRET technology, as previously described (Abdulrahman et al., 2016). The assay measures the physical recruitment of the IRS1-YFP protein to hIR-Rluc upon its activation in live cells, as described in Figure 2A. As expected, insulin promoted a dose-dependent increase in the BRET signal between hIR-Rluc and IRS1-YFP with the expected potency (Figure 2B; Supplemental Table S2, https://doi.org/10 .3168/jds.2020-18627), indicating successful validation of BRET as a readout for hIR activation. Similarly, raw CWP partially and significantly increased the BRET signal (Figure 2C). Interestingly, the competitive hIR- selective peptide antagonist S961 drastically inhibited the increase of insulin-induced but not CWP-induced BRET (Figure 2D). This demonstrated that BRET signals indeed reflect hIR activation by insulin and suggests a different mode of action of CWP on hIR. To link BRET data with the phosphorylation status of hIR, we also looked at hIR phosphorylation at Tyr1334 upon treatment of cells with either insulin $(1 \mu M)$ or CWP $(1 \mathrm{mg} / \mathrm{mL})$. As shown in Figure $2 \mathrm{E}$, both insulin and CWP promoted a significant hIR phosphorylation in HEK293 cells. Together, BRET and phosphorylation data on hIR reveal positive effects of CWP on hIR activity in HEK293 cells, suggesting either a direct or an indirect action on hIR.

\section{Profiling of CWP Peptide Hydrolysates on hIR Activity in HEK293 Cells}

Next, we profiled 4 CWP hydrolysates, H3, H5, H11, and H12, selected based on their differential inhibitory action on DPP-IV activity (Table 2) and examined their biological activity on hIR activity in cells. For this, both hIR activation by BRET assay and its phosphorylation status were examined using $1 \mathrm{mg} / \mathrm{mL}$ of each peptide hydrolysate, along with raw CWP and insulin as the positive controls. As shown in Figure 3A, CWP and their peptide hydrolysates increased the BRET signal to different extents, compared with insulin. The effect of the CWP peptide hydrolysates occurred in a dose-response manner (Figure 3B). These data indicate the intact bioactivity of CWP hydrolysates on hIR, as shown for their inhibitory action on DPP-IV (Table 2). As in Figure 2D, although treatment with S961 drastically inhibited the insulin-mediated BRET signal, this had no significant effect on the BRET signals promoted by CWP and their different peptide hydrolysates (Figure $3 \mathrm{C}$ ). To rule out any artifact in the BRET assays that may lead to a nonspecific BRET increase between hIR-Rluc and IRS1-YFP, we used the angiotensin II type 1 receptor $(\mathbf{A T} 1 \mathbf{R})$ as a nonrelevant hormone receptor. We also measured the BRET related to the interaction between AT1R and its cognate heterotrimeric Gq protein. For this, the different camel milk fractions were tested via the BRET process that occurs between AT1R-Rluc (as donor) and Venus-Gq (as acceptor), using the natural hormone angiotensin II (AngII) as a positive control. As shown in Figure 3D, none of the different camel milk fraction promoted a significant change in the BRET signal, whereas AngII $(1 \mu M)$ did. This clearly demonstrates the specificity of the observed effects of the camel milk fractions on hIR activity measured by BRET assay.

Moreover, the positive effect of the CWP peptide hydrolysates on hIR was demonstrated by the significant 
A)

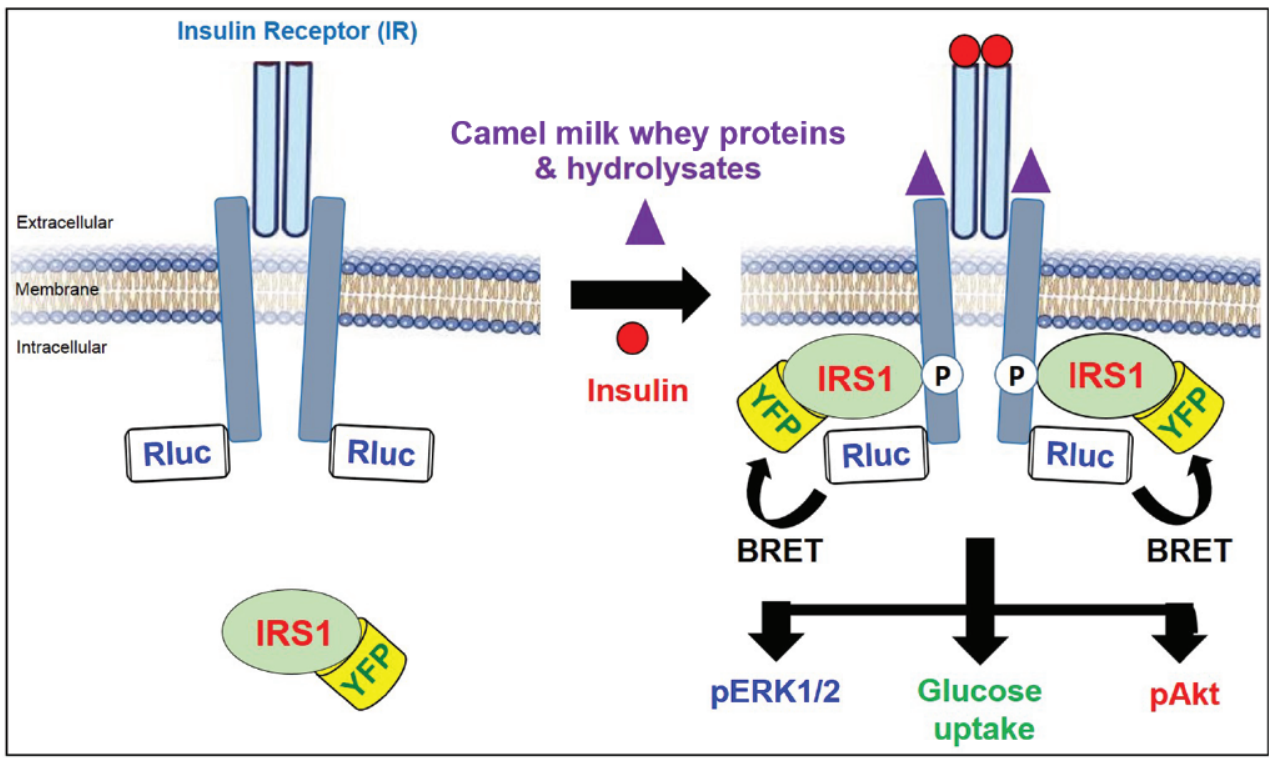

B)

C)
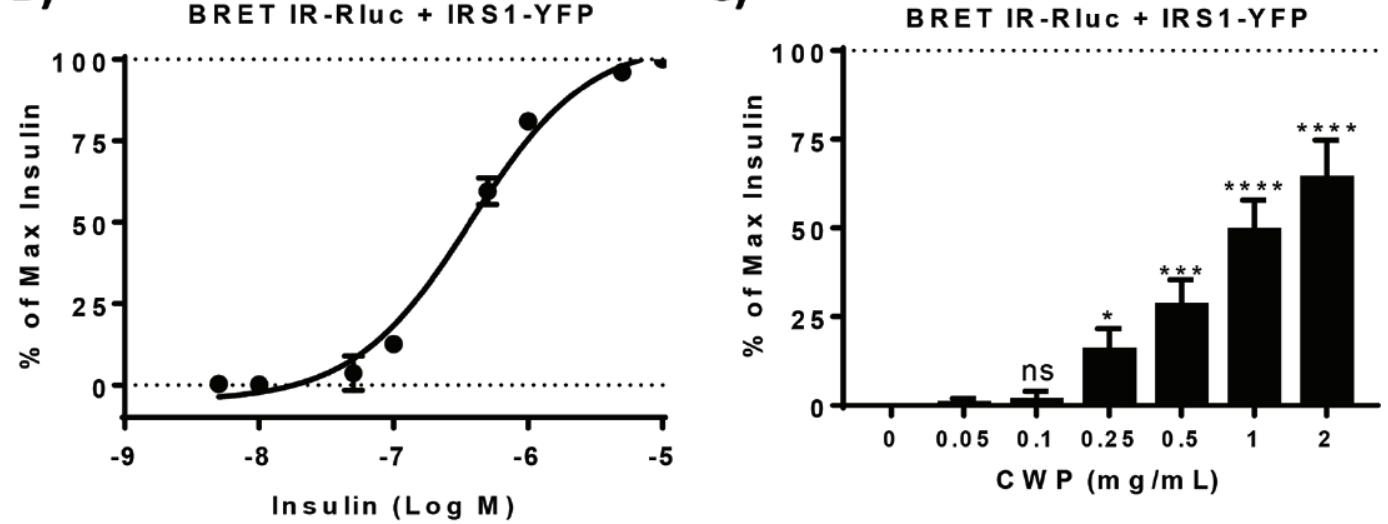

D)

E)

hIR-transfected HEK293
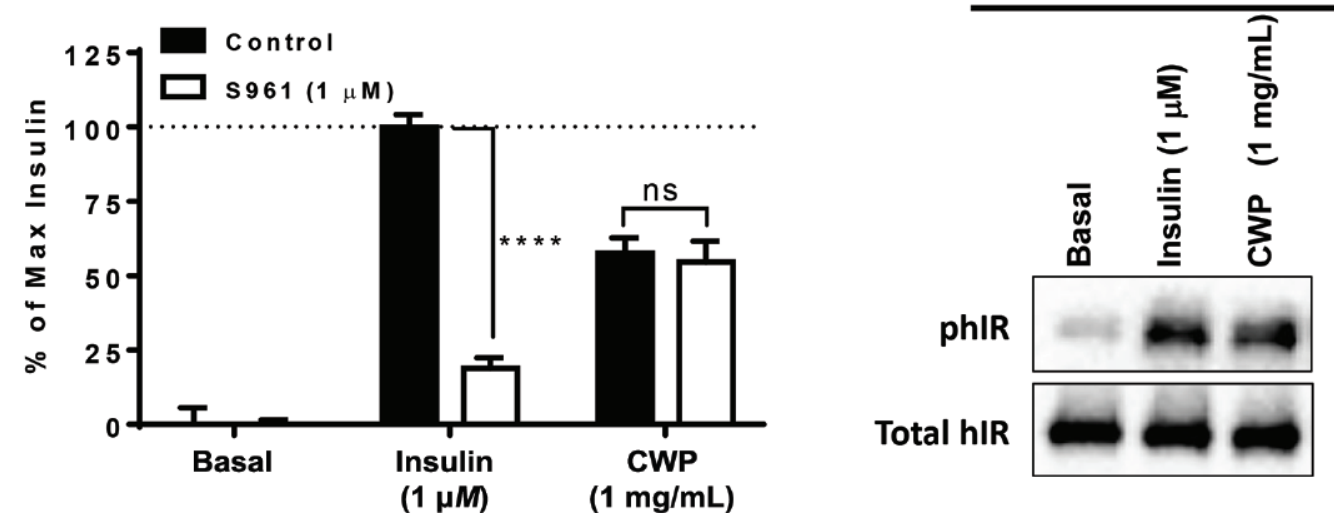

Figure 2. Positive effects of camel whey proteins (CWP) on human insulin receptor (hIR) activity in human embryonic kidney cells (HEK293). (A) Principle of bioluminescence resonance energy transfer (BRET) assay in HEK293 cells transiently coexpressing hIR-Renilla luciferase (Rluc) and insulin receptor substrate 1-yellow fluorescent protein (IRS1-YFP) and treated or not treated with insulin or camel milk fractions. (B) Dose-response of insulin on BRET signal. (C) Dose-response of CWP on BRET signal. (D) BRET assay in the absence or presence of the antagonist S961 $(1 \mu M)$. (E) Phosphorylation status of hIR in cells treated or not treated with insulin $(1 \mu M)$ or CWP $(1 \mathrm{mg} / \mathrm{mL})$. BRET data are means \pm SEM of 5 independent experiments performed in triplicate. ${ }^{* * * *} P<0.0001,{ }^{* * *} P<0.001,{ }^{* *} P<0.01,{ }^{*} P<0.05$, ns $=$ not significant $(P>0.05)$ 
A)

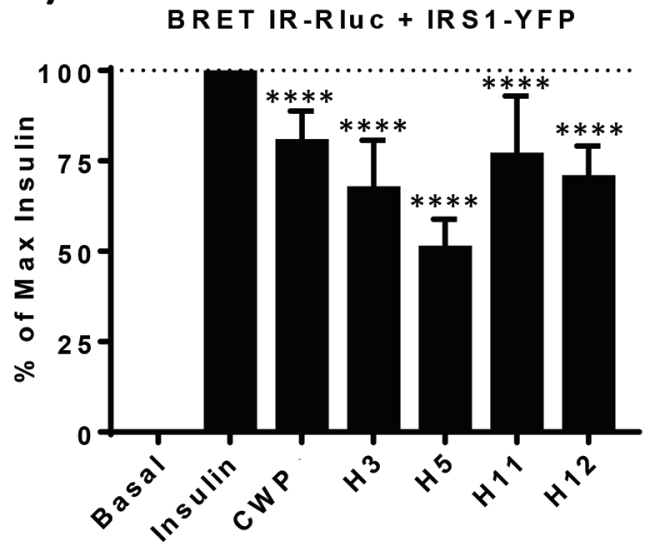

C)

BRET IR-Rluc + IRS1-YFP
B)

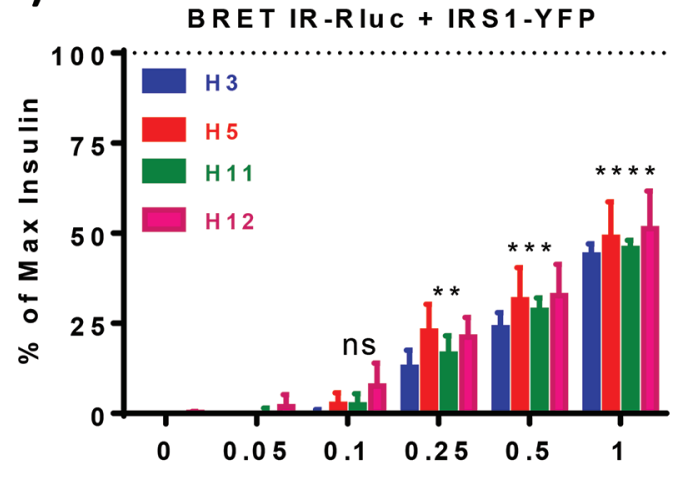

C W P hydrolysates ( $\mathrm{mg} / \mathrm{m} \mathrm{L})$

D)
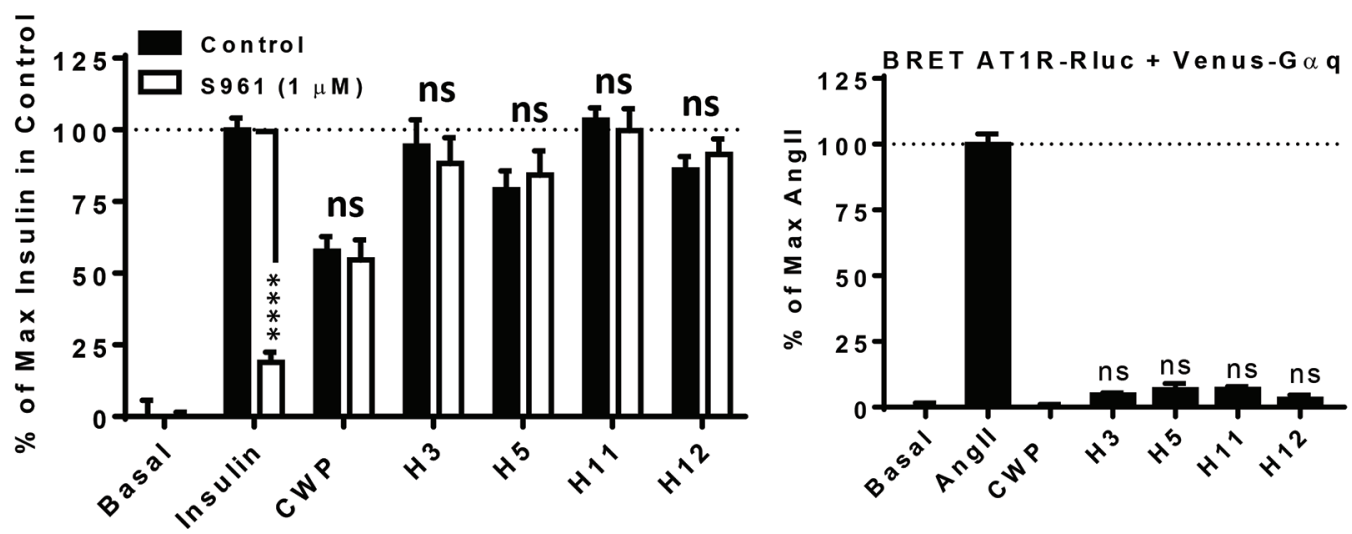

E)

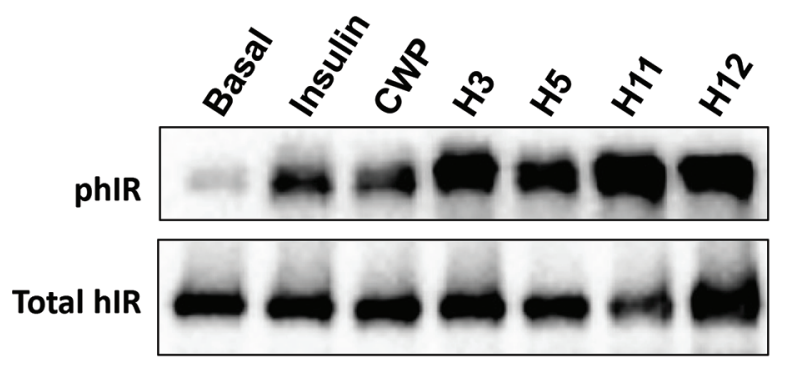

F)

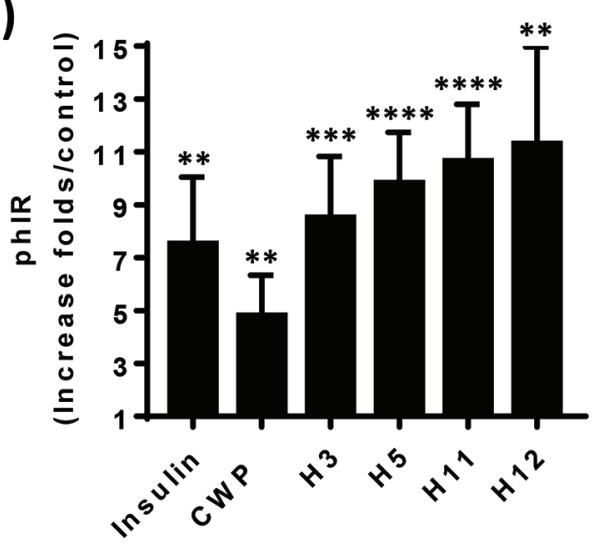

Figure 3. Positive effects of camel whey protein hydrolysates (CWPH) on human insulin receptor (hIR) activity in human embryonic kidney cells (HEK293). HEK293 cells transiently coexpressing hIR-Renilla luciferase (Rluc) and insulin receptor substrate 1-yellow fluorescent protein (IRS1-YFP) were treated or not treated with either a single dose of insulin $(1 \mu M)$, camel whey protein $(\mathrm{CWP} ; 1 \mathrm{mg} / \mathrm{mL})$, and $\mathrm{CWPH}(\mathrm{H} 3$, $\mathrm{H} 5, \mathrm{H} 11$, and $\mathrm{H} 12$ at $1 \mathrm{mg} / \mathrm{mL}$ ) (A), or increasing doses of CWPH (B). (C) Bioluminescence resonance energy transfer (BRET) assay in the absence or presence of the antagonist S961 $(1 \mu M$ ). (D) BRET assay in HEK293 cells coexpressing AT1R-Rluc and Venus-Gaq and treated or not treated with angiotensin II (AngII; $1 \mu M)$, CWP $(1 \mathrm{mg} / \mathrm{mL}$ ), or CWPH $(1 \mathrm{mg} / \mathrm{mL})$. (E) Representative phosphorylation status of hIR (phIR) in HEK293 cells treated or not treated with insulin $(1 \mu M)$, CWP $(1 \mathrm{mg} / \mathrm{mL})$, or CWPH $(1 \mathrm{mg} / \mathrm{mL})$. (F) Quantification of Western blot data for hIR phosphorylation using densitometry analysis; bars are means \pm SEM of 4 independent experiments. BRET data are means \pm SEM of 4-8 independent experiments performed in triplicate. ${ }^{* * * *} P<0.0001,{ }^{* * *} P<0.001,{ }^{* *} P<0.01$, ns $=$ not significant $(P>0.05)$. 
A)

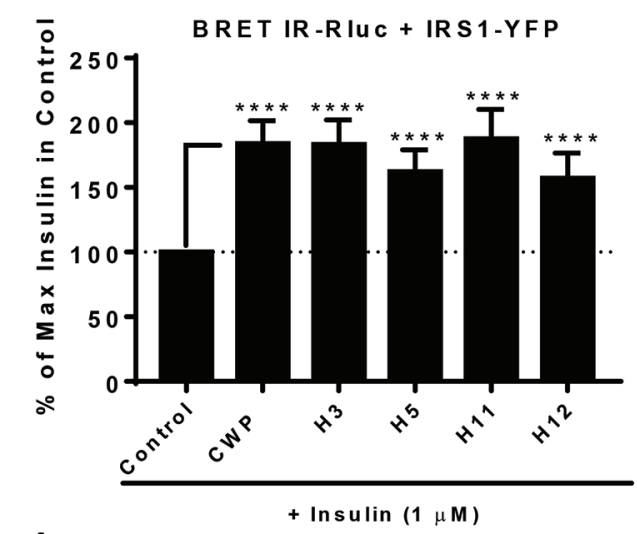

C)

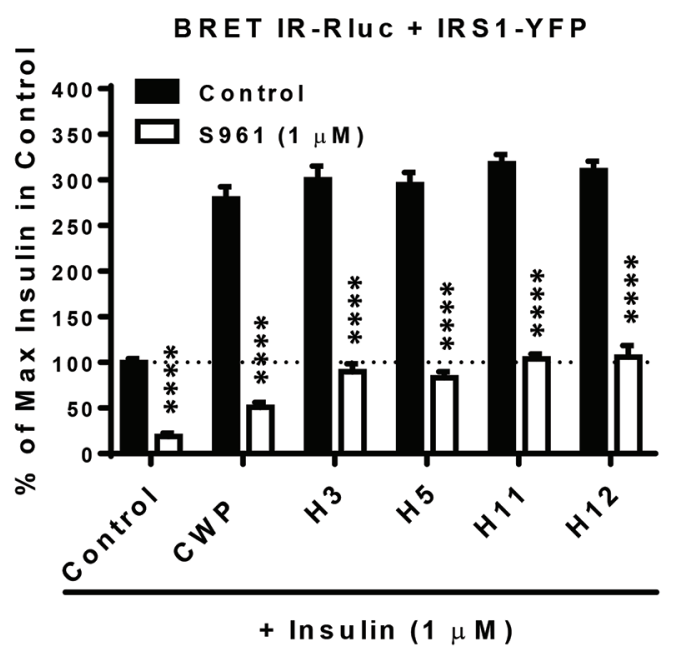

B)

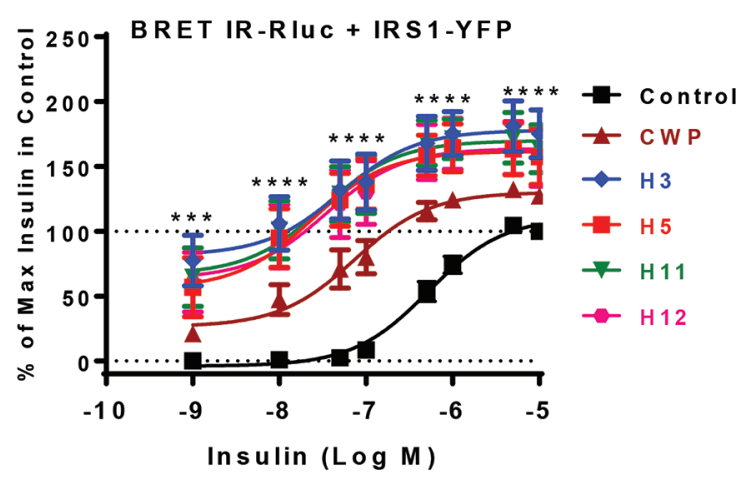

D)

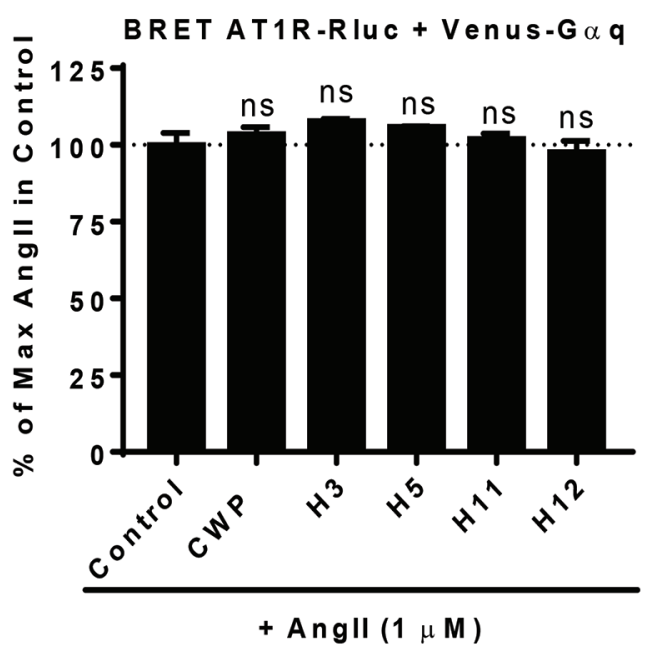

E)

+ Insulin

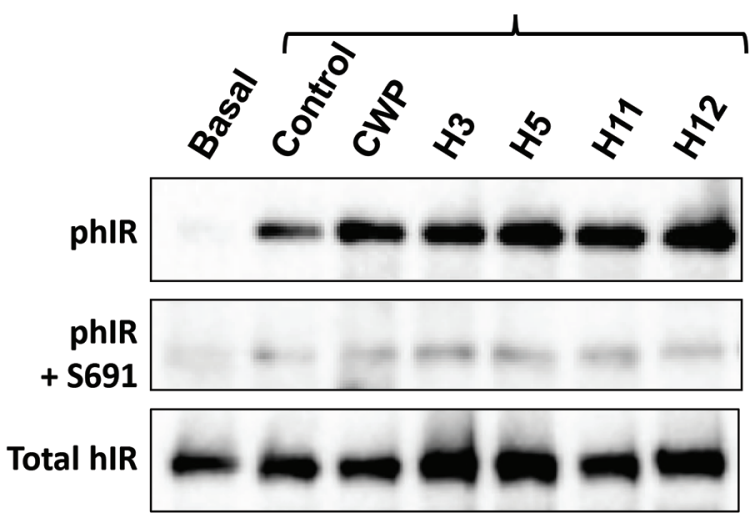

Figure 4. Positive allosteric effects of camel whey proteins (CWP) and camel whey protein hydrolysates (CWPH) on human insulin receptor (hIR) activity in human embryonic kidney cells (HEK293). HEK293 cells transiently coexpressing hIR-Renilla luciferase (Rluc) and insulin receptor substrate 1-yellow fluorescent protein (IRS1-YFP) were treated or not treated with $1 \mu M(\mathrm{~A}, \mathrm{C})$ or increasing doses (B) of insulin in the absence or presence of either CWP $(1 \mathrm{mg} / \mathrm{mL}$ ) or CWPH (H3, H5, H11, and H12 at $1 \mathrm{mg} / \mathrm{mL}$ ) as indicated. (C) Bioluminescence resonance energy transfer (BRET) assay in the absence or presence of the antagonist S961 $(1 \mu M)$. (D) BRET assay in HEK293 cells coexpressing AT1RRluc and Venus-Gaq and treated or not treated with angiotensin II (AngII; $1 \mu M$ ) in the absence or presence of either CWP $(1 \mathrm{mg} / \mathrm{mL}$ ) or CWPH $(1 \mathrm{mg} / \mathrm{mL})$. (E) Representative experiment for the phosphorylation status of hIR (phIR) in HEK293 cells treated or not treated with insulin $(1 \mu M)$ in the absence or presence of either CWP $(1 \mathrm{mg} / \mathrm{mL})$ or CWPH $(1 \mathrm{mg} / \mathrm{mL})$. BRET data are means \pm SEM of $4-8$ independent experiments performed in triplicate. ${ }^{* * * *} P<0.0001,{ }^{* * *} P<0.001, \mathrm{~ns}=$ not significant $(P>0.05)$. 


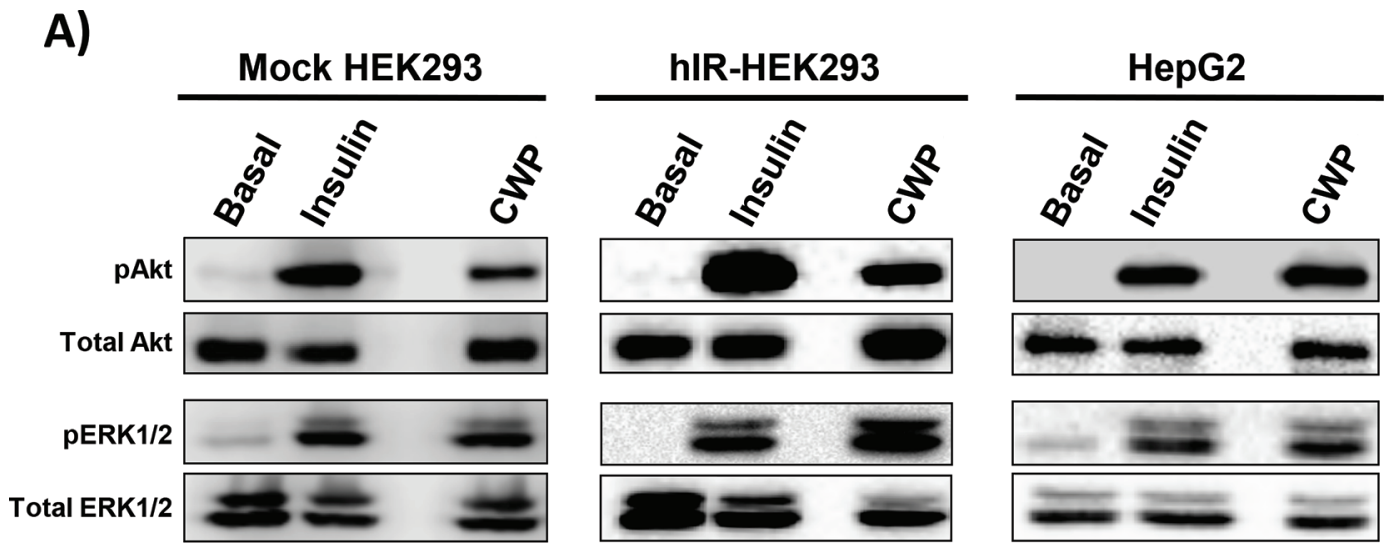

B)

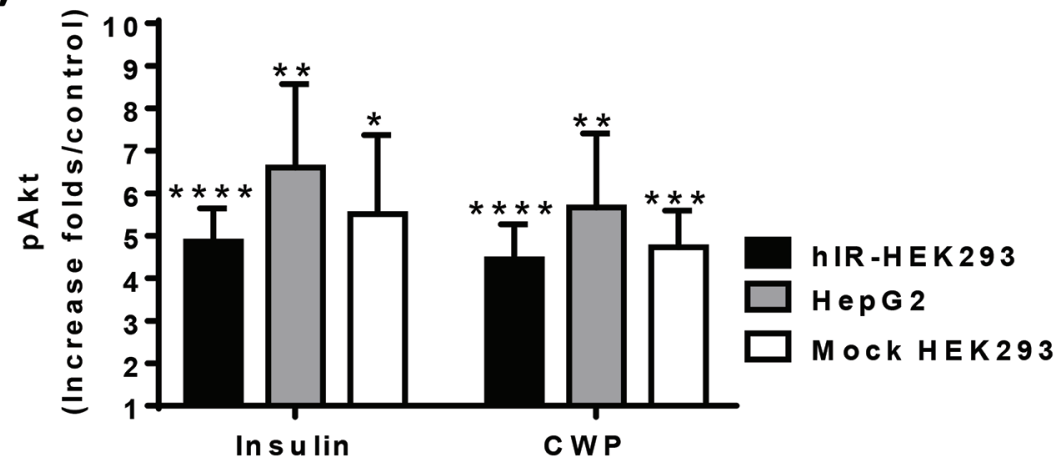

C)

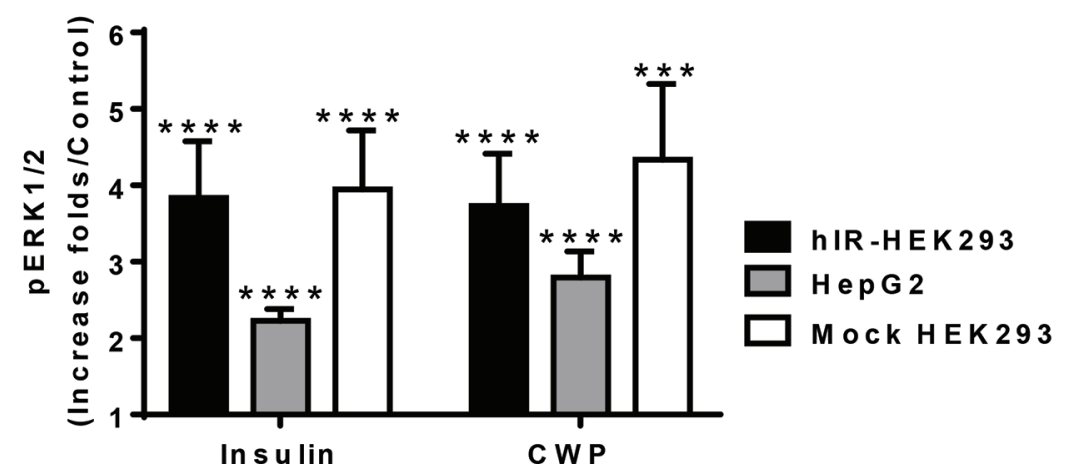

Figure 5. Positive effects of camel whey proteins (CWP) on Akt and extracellular signal-regulated kinases 1/2 (ERK1/2) activation in human embryonic kidney cells (HEK293) and human hepatocellular carcinoma cells (HepG2). Mock HEK293 cells, HEK293 cells transiently expressing human insulin receptor-Renilla luciferase (hIR-Rluc), and HepG2 cells endogenously expressing hIR were treated or not treated with either insulin $(1 \mu M)$ or CWP $(1 \mathrm{mg} / \mathrm{mL})$ as indicated, and Akt and ERK1/2 phosphorylation (p) was assessed by Western blot (A). (B, C) Quantification of Western blot data for Akt and ERK1/2 phosphorylation, respectively, using densitometry analysis. Bars are means \pm SEM of 4-8 independent experiments. $* * * * P<0.0001, * * * P<0.001,{ }^{* *} P<0.01, * P<0.05$.

increase in its phosphorylation status in HEK293 cells, similarly to insulin and raw CWP (Figure 3E and F).

\section{Positive Allosteric Effects of CWP and Peptide Hydrolysates on HIR}

The fact that the competitive hIR antagonist (S961) blocked the insulin-mediated BRET response but not those of CWP and CWPH (Figure 3C) suggests a different mode of action on hIR. Therefore, we wanted to test the possible positive allosteric effects of CWP and CWPH on hIR, as previously suggested (Abdulrahman et al., 2016; Ayoub et al., 2018). For this, we applied combined stimulations of the cells coexpressing hIR-Rluc and IRS1-YFP with insulin $(1 \mu M)$ in the presence of $1 \mathrm{mg} / \mathrm{mL}$ of either raw CWP or CWPH. 
As shown in Figure 4A, the co-treatment with CWP or CWPH significantly potentiated, to different extents, the insulin-mediated BRET signals. Such a positive effect was also confirmed on insulin dose-response, show- ing an increase in both the efficacy and the potency of insulin (Figure 4B; Supplemental Table S2, https://doi .org/10.3168/jds.2020-18627) and revealing a positive allosteric action of CWP and CWPH on hIR. More

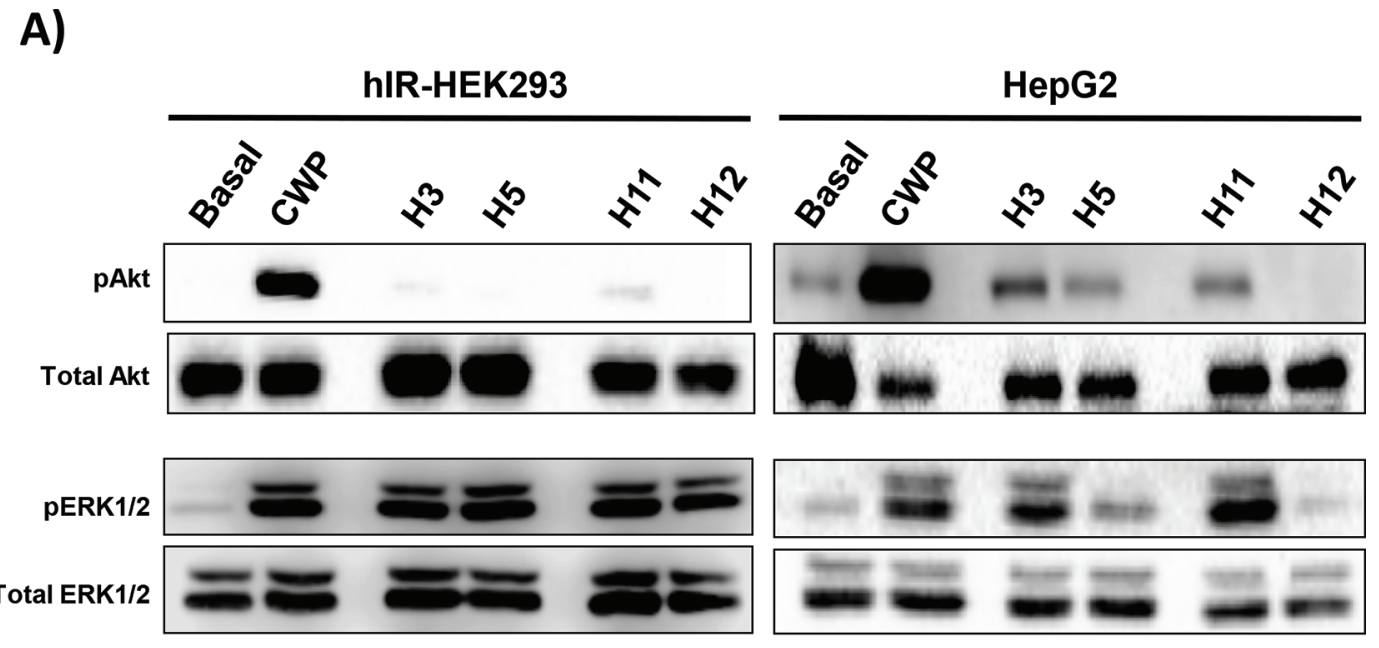

B)
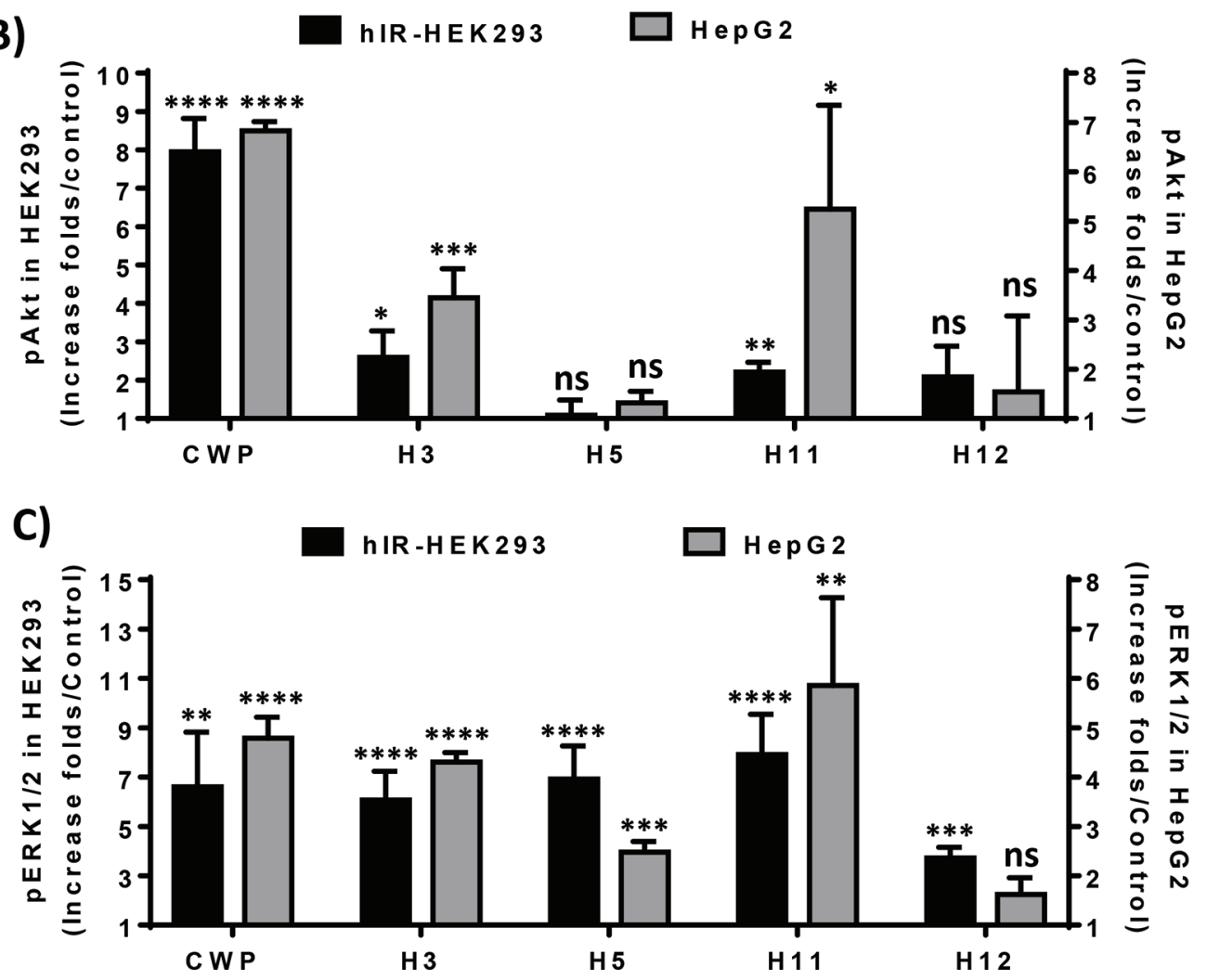

Figure 6. Positive effects of camel whey protein hydrolysates (CWPH) on Akt and extracellular signal-regulated kinases 1/2 (ERK1/2) activation in human embryonic kidney cells (HEK293) and human hepatocellular carcinoma cells (HepG2). HEK293 cells transiently expressing human insulin receptor-Renilla luciferase (hIR-Rluc) and HepG2 cells endogenously expressing hIR were treated or not treated with 1 mg/mL of either camel whey protein (CWP) or CWPH (H3, H5, H11, and H12) as indicated, and Akt and ERK1/2 phosphorylation (p) was assessed by Western blotting (A). (B, C) Quantification of Western blot data for Akt and ERK1/2 phosphorylation, respectively, using densitometry analysis. Bars are means \pm SEM of $3-8$ independent experiments. ${ }^{* * * *} P<0.0001,{ }^{* * *} P<0.001,{ }^{* *} P<0.01,{ }^{*} P<0.05$, ns $=$ not significant $(P>0.05)$. 
interestingly, the antagonist S691 drastically reduced the potentiation of the BRET signals induced by the raw CWP and CWPH (Figure 4C). It is worth noting that the remaining BRET response reflects the direct effects of the different camel milk fractions on hIR, as shown in Figure 3. This clearly suggests allosteric effects of raw CWP and CWPH on hIR that require its activation by insulin. Such effects were specific to hIR, because no BRET potentiation by CWP or $\mathrm{CWPH}$ was observed on the BRET signal mediated by AngII between ATR1-Rluc and Venus-Gq (used here as a negative control). (Figure 4D). Moreover, the insulinpromoted hIR phosphorylation was also potentiated by the co-treatment and strongly inhibited by the antagonist S961, further indicating the specific targeting of hIR by raw CWP and CWPH (Figure 4E).

\section{CWP Induces Phosphorylation of Akt and ERK1/2}

To further explore the potential pharmacological action of CWP on hIR, we investigated the functional activity of CWP on the phosphorylation status of Akt and ERK1/2, representing the 2 major hIR-mediated downstream signaling pathways known to control glucose uptake and homeostasis. For this, we used 2 different cells models: HepG2 cells endogenously expressing hIR, and HEK293 cells transiently expressing or not expressing hIR. Interestingly, CWP strongly induced Akt and ERK1/2 phosphorylation in HEK293 and HepG2 cells, similarly to the action of insulin (Figure 5A). The effects of insulin and CWP were statistically significant over 3 to 8 independent experiments, as shown in the quantification of the Western blot data for pAkt (Figure 5B) and pERK1/2 (Figure 5C). These data demonstrate the functional activity of camel milk whey proteins on Akt and ERK1/2 signaling pathways in the different cell lines.

\section{Profiling of CWPH on Akt and ERK1/2 Pathways}

Next, we examined the effects of $\mathrm{H} 3, \mathrm{H} 5, \mathrm{H} 11$, and H12 on Akt and ERK1/2 phosphorylation. As shown in Figure 6A, the peptide hydrolysates showed different extents of Akt and ERK1/2 phosphorylation, with stronger effect on ERK1/2 relative to Akt, especially in HEK293 cells. The trends showed H3, H5, and H11 being stronger than $\mathrm{H} 12$ in all cases (Figure 6A, B, and C). Together, these observations are consistent with those obtained with intact CWP and demonstrate the biological activity of peptide hydrolysates obtained from pepsin hydrolysis of whole CWP on Akt and ERK1/2 signaling pathways in HEK293 and HepG2 cell lines.

\section{Positive Effects of CWP and Hydrolysates on Glucose Uptake}

To translate BRET and phosphorylation data into more integrated cell response and to make a link with the hypoglycemic properties of camel milk demonstrated in many in vivo studies, we also examined the effects of intact CWP and selected hydrolysates on glucose uptake in HepG2 cells. As shown in Figure 7, unexpectedly in contrast to insulin, all the other treatments significantly $(P<0.0001, \mathrm{n}=5)$ and to different extents promoted glucose uptake in HepG2 cells. The absence of glucose uptake upon insulin stimulation may be due to the differences in the type of glucose transporter expressed in HepG2 cells and used or not used by insulin and camel milk proteins and peptides.

\section{DISCUSSION}

In this study, we investigated for the first time the molecular basis of the anti-diabetic properties of camel milk in vitro, using different models and approaches. For this, we targeted 2 key pathways in the regulation of glucose homeostasis and diabetes, the enzyme DPP-IV and the human insulin receptor, hIR. This was based on our hypothesis that the hypoglycemic properties of camel milk may involve a pharmacological action of camel milk protein or peptide components on these 2 pathways, because DPP-IV controls insulin secretion by the $\beta$-pancreatic cells through the incretins GLP-1 and GIP, and hIR mediates the biological effects of insulin in the major insulin-sensitive tissues. Thus, we focused on camel milk whey, as a major source of proteins and peptides, for profiling their inhibitory effects on DPP-IV activity and their potential pharmacological actions on hIR activity and downstream signaling, as well as glucose uptake in cell lines. We first generated CWPH by pepsin hydrolysis, with a significant increase in the degree of hydrolysis with the time of hydrolysis. Nongonierma et al. (2019) have also reported that AN content of CWPH generated by trypsin demonstrated an increase with increase in E:S (\%) and time of hydrolysis. Upon hydrolysis, the major whey proteins have demonstrated complete degradation and generated shorter peptides, which eluted toward lower retention time compared with the major whey proteins, as previously reported (Nongonierma et al., 2019), indicating that camel milk protein hydrolysates contained peptides with a wide range of hydrophobicity (Figure 1). Similar results for peptide profile of camel whey protein hydrolysates generated with gastric and pancreatic enzymes were also previously reported (Kamal et al., 2018). 
This study's interesting findings demonstrate the bioactivity of raw CWP and CWPH on different pathways: DPP-IV activity in vitro, hIR function and signaling in HEK293 and HepG2 cells, and glucose uptake in HepG2 cells. Suppression of incretin degradation by DPP-IV inhibitors is sought to improve insulin secretion and recovers glycemic control. Thus, DPP-IV inhibitors are proposed to have potential for the management of type 2 diabetes (Richter et al., 2008; Nongonierma and FitzGerald, 2019). It has been reported that peptides produced from whey proteins possess potent DPP-IV inhibitory properties (Gaudel et al., 2013; Nongonierma et al., 2019). In the present study, it was observed that CWPH generated using pepsin displayed higher DPP-IV inhibitory activity compared with intact CWP. It has been reported that an increase in $\mathrm{E}: \mathrm{S}$ or in the temperature of hydrolysis would affect the $\mathrm{IC}_{50}$ value by reducing the DPP-IV inhibitory properties (Maqsood et al., 2019). Moreover, milk proteins have been found to encrypt effective DPP-IV inhibitory peptides, which have been analyzed by in silico studies (Lacroix and Li-Chan, 2013). Recently, peptic camel whey protein hydrolysates showed the highest DPP-IV inhibition (92-96\%), followed by trypsin- and chymotrypsin-generated CWPH (Kamal et al., 2018). The results obtained corroborate well with previous studies reported by Nongonierma et al. (2017), wherein trypsin digestion of bovine milk protein produced hydrolysates with DPP-IV $\mathrm{IC}_{50}$ values ranging from 0.68 to $1.59 \mathrm{mg} /$ $\mathrm{mL}$. The observed $\mathrm{IC}_{50}$ values were, however, far lower than those obtained from peptic hydrolysates of bovine whey protein hydrolysates $(0.075 \mathrm{mg} / \mathrm{mL}$; Lacroix and Li-Chan, 2013). Further, the DPP-IV inhibitory activities of CWPH were substantially better than those obtained by Tagliazucchi et al. (2018), who found that hydrolysates obtained from gastrointestinal digestion of cow, camel, goat, and sheep milk proteins presented DPP-IV $\mathrm{IC}_{50}$ values of $6.9,17.2,15.3$, and $16.3 \mathrm{mg} /$ $\mathrm{mL}$, respectively. Literature related to the properties of DPP-IV inhibitory bioactive peptides suggests that these peptides are vividly diverse in terms of size, amino acid sequences, and characteristics. Some reports suggest that smaller peptides, usually less than 8 amino acids long, have lower $\mathrm{IC}_{50}$ than longer peptides. However, it has been reported that even peptides with a chain length of more than 13 amino acids can exert potent DPP-IV inhibition by inhibiting the formation of protein dimer of DPP-IV (Velarde-Salcedo et al., 2013). Usually it is indicated that peptides with $\mathrm{IC}_{50}$ $<100 \mathrm{~m} M$ are dipeptides with Trp, Thr, and Met at their $\mathrm{N}$ terminus and Ala, Leu, and His at their Cterminus.

Peptide sequencing of the selected CWPH (H3, H5, H11, and H12) identified 43, 48, 44, and 48 peptides, respectively (Supplemental Table S1, https://doi .org/10.3168/jds.2020-18627). Previous studies have shown that DPP-IV possesses Ser630, Asp708, His740, Gly629, Gly633, Tyr631, Glu205, and Glu206 as important amino acid residues at its active sites (Lambeir et al., 2003). Overall, 3 amino acids, Ser630, Asp708,

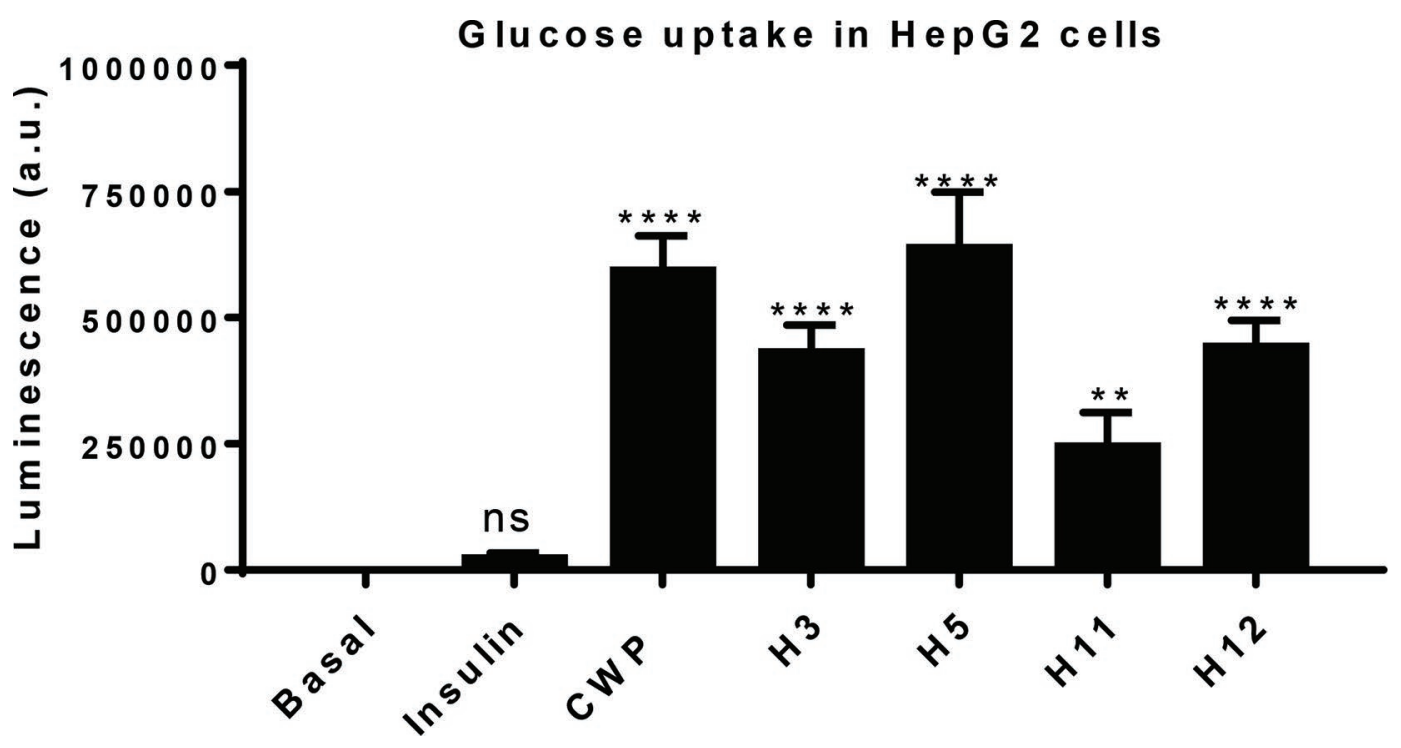

Figure 7. Positive effects of camel whey protein (CWP) and camel whey protein hydrolysates (CWPH) on glucose uptake in human hepatocellular carcinoma cells (HepG2). HepG2 cells endogenously expressing human insulin receptor (hIR) were treated or not with either insulin (1 $\mu M)$, CWP $(1 \mathrm{mg} / \mathrm{mL})$, or CWPH (H3, H5, H11, and $\mathrm{H} 12$ at $1 \mathrm{mg} / \mathrm{mL})$ as indicated, and glucose uptake was measured in live cells. Data are means \pm SEM of 5 independent experiments performed in triplicate. a. u. $=$ arbitrary units. $* * * * P<0.0001,{ }^{*} P<0.01$, ns $=$ not significant $(P>0.05)$. 
and His740, are known as the main catalytic triad and are regarded as the main interactive residue in DPP-IV during its inhibition. In addition, most commercially available DPP-IV enzyme inhibitors, such as vildapliptin and saxagliptin, are known to interact with Ser630, Tyr666, Tyr547; alogliptin and linagliptin with Tyr547 and Trp629; and sitagliptin and teneligliptin with Asn710 (Nabeno et al., 2013). Hence, these amino acids are considered potential indicators of the interaction of DPP-IV with bioactive peptides and are the main focus for future research on new DPP-IV inhibitors (Bjelke et al., 2004). Prominence of hydrophobic amino acids in peptides is considered an additional factor for DPP-IV inhibition because these amino acids may further enhance interaction with the active site of DPP-IV, as the S1 subsite of the DPP-IV active site contains hydrophobic pockets that have been reported to play a critical role in DPP-IV inhibition. The importance of hydrophobic, acidic, and bulky amino acids for enhancing the DPP-IV inhibitory activity has also been emphasized (Nongonierma and FitzGerald, 2019). Overall, we observed that the peptides obtained in the present study act as competitive inhibitors for DPPIV substrate by binding to and inhibiting the enzyme activity of DPP-IV. Indeed, CWP effectively inhibited DPP-IV with an $\mathrm{IC}_{50}$ of $8.46 \mathrm{mg} / \mathrm{mL}$, suggesting that this mechanism of action may be involved in the hypoglycemic effects of camel milk, as previously discussed (Ayoub et al., 2018; Kamal et al., 2018). Thus, peptides rich in these amino acids can be produced and synthesized as potential DPP-IV inhibitors for future research.

To further characterize the molecular mechanisms of the anti-diabetic properties of camel whey proteins, we also assessed CWPH activity on hIR and its downstream signaling, as well as glucose uptake. Interestingly, CWP positively modulate hIR activity, as demonstrated by BRET in HEK293 cells, as well as its downstream signaling, illustrated by the phosphorylation of hIR, associated with the phosphorylation of its major intracellular kinases, Akt and ERK1/2, observed in both HEK293 and HepG2 cells. This is consistent with our previous study performed on camel milk from Saudi Arabia (Abdulrahman et al., 2016), supporting the hypothesis that the hypoglycemic effects of camel milk involve a molecular targeting of $\mathrm{hIR}$ and its intracellular signaling pathways. Surprisingly, the competitive hIR antagonist S961 did not block the pharmacological effect of CWP on hIR, whereas it effectively did block the effects of insulin, suggesting a different mode of action of CWP independently on the orthosteric binding site on hIR. This may involve either a positive allosteric modulation of CWP and CWPH directly on hIR, as we previously suspected (Abdulrahman et al., 2016), or an indirect effect via another cell surface receptor or protein that crosstalks with hIR. Indeed, the co-treatment of cells with insulin and CWP and hydrolysates resulted in a potentiation of the insulin effect (potency and efficacy) on hIR activity, which was effectively blocked by S961 (Figure 4; Supplemental Table S2, https://doi.org/10 $.3168 /$ jds.2020-18627). This is typically indicative of CWP and CWPH exerting a positive allosteric modulation on hIR that requires insulin binding on hIR, suggesting the existence of an allosteric binding site on hIR where CWP and their derived peptides can bind effectively. Allosteric modulation on hIR has been reported in previous studies using selective antibodies (Bhaskar et al., 2012; Issafras et al., 2014). Alternatively, such an allosteric effect on hIR may pass through an indirect way involving another receptor expressed in HEK293 cells that functionally or physically interact with hIR. This may result in the functional transactivation between 2 receptors at the cell surface or even crosstalk in their respective intracellular signaling pathways, leading to potentiation of insulin or hIR function. This interesting aspect needs further investigation. Moreover, our study provides cellular evidence for the first time that camel milk promotes glucose transport inside live cells. Indeed, we demonstrated that CWP and its hydrolysates significantly promoted glucose uptake in HepG2 cells. Surprisingly, our data showed a very weak insulin-mediated glucose uptake compared with camel milk fractions. This may be due to the differences in the type of glucose transporter expressed in HepG2 cells and used or not used by insulin and camel milk proteins and peptides.

The dual effects of CWP and their hydrolysates on DPP-IV (negative) and hIR (positive) constitute an interesting feature of camel milk that may explain its substantial anti-diabetic effects. This clearly demonstrates the targeting of 2 major pathways, insulin secretion and its action in the sensitive tissues, involved in the control of glucose homeostasis and diabetes. However, our study does not indicate whether such dual effects are mediated by the same proteins or peptide fractions contained in CWP. Our in silico analysis on DPP-IV inhibitory peptides indicated the binding properties of the 4 potential peptides and highlighted key binding sites between the peptide sequences and key residues in DPP-IV. Thus, it would be interesting to perform a similar analysis on $\mathrm{hIR}$ and to correlate with our peptide in silico binding data on DPP-IV. This aspect is being considered for further investigation. Finally, our findings demonstrate for the first time the biological activity of CWP hydrolysates at the molecular and cellular levels and further support our hypothesis that the anti-diabetic properties of camel milk may be mediated by bioactive peptides upon camel milk consump- 
tion and digestion, as previously discussed (Malik et al., 2012; Ayoub et al., 2018). This moves research one step further in the identification and characterization of the anti-diabetic agent contained in camel milk and opens interesting perspectives for the development of new anti-diabetic drugs from camel milk products.

\section{ACKNOWLEDGMENTS}

This work was supported by a United Arab Emirates University (UAEU) startup grant (31S305) and a UAEU-Zayed Center for Health Sciences (ZCHS) grant (31R235) to MAA, UAEU Program for Advanced Research (UPAR) grant (31F094) to SM, and Universiti Sains Malaysia Research University Individual (USM RUI) grant (1001/CABR/8011045) to CG. Hassan M. Hassan (Department of Food, Nutrition and Health, College of Food and Agriculture, UAEU) is acknowledged for performing reverse-phase ultra performance liquid chromatography analysis of the hydrolysates. AA performed BRET, phosphorylation, and glucose uptake experiments; PM fractionated camel milk and characterized the hydrolysates and performed the DPP-IV assay; AP contributed to cell transfection, phosphorylation, and glucose uptake experiments; RI contributed to cell transfection, phosphorylation experiments, and data analysis; CG performed peptide sequencing; SM designed the project, performed in silico analysis, analyzed the data, and wrote and finalized the manuscript; and MAA designed the project, performed BRET experiments, analyzed the data, and wrote and finalized the manuscript. There are no conflicts of interest to declare.

\section{REFERENCES}

Abdulrahman, A. O., M. A. Ismael, K. Al-Hosaini, C. Rame, A. M. Al-Senaidy, J. Dupont, and M. A. Ayoub. 2016. Differential effects of camel milk on insulin receptor signaling-Toward understanding the insulin-like properties of camel milk. Front. Endocrinol. (Lausanne) 7:4. https://doi.org/10.3389/fendo.2016.00004.

Agrawal, R. P., R. Beniwal, D. K. Kochar, F. C. Tuteja, S. K. Ghorui, M. S. Sahani, and S. Sharma. 2005. Camel milk as an adjunct to insulin therapy improves long-term glycemic control and reduction in doses of insulin in patients with type-1 diabetes: A 1 year randomized controlled trial. Diabetes Res. Clin. Pract. 68:176-177. https://doi.org/10.1016/j.diabres.2004.12.007.

Agrawal, R. P., S. Jain, S. Shah, A. Chopra, and V. Agarwal. 2011. Effect of camel milk on glycemic control and insulin requirement in patients with type 1 diabetes: 2-years randomized controlled trial. Eur. J. Clin. Nutr. 65:1048-1052. https://doi.org/10.1038/ ejcn.2011.98.

Agrawal, R. P., P. Tantia, S. Jain, R. Agrawal, and V. Agrawal. 2013. Camel milk: A possible boon for type 1 diabetic patients. Cell. Mol. Biol. 59:99-107.

Alavi, F., M. Salami, Z. Emam-Djomeh, and M. Mohammadian. 2017. Nutraceutical properties of camel milk. Pages 451-468 in Nutrients in Dairy and their Implications on Health and Disease. Elsevier, Amsterdam, the Netherlands.
Ali, A., A. Palakkott, A. Ashraf, I. Al Zamel, B. Baby, R. Vijayan, and M. A. Ayoub. 2019. Positive modulation of angiotensin II type 1 receptor-mediated signaling by LVV-hemorphin-7. Front. Pharmacol. 10:1258. https://doi.org/10.3389/fphar.2019.01258.

Ayoub, M. A., A. R. Palakkott, A. Ashraf, and R. Iratni. 2018. The molecular basis of the anti-diabetic properties of camel milk. Diabetes Res. Clin. Pract. 146:305-312. https://doi.org/10.1016/j .diabres.2018.11.006.

Bhaskar, V., I. D. Goldfine, D. H. Bedinger, A. Lau, H. F. Kuan, L. M. Gross, M. Handa, B. A. Maddux, S. R. Watson, S. Zhu, A. J. Narasimha, R. Levy, L. Webster, S. D. Wijesuriya, N. Liu, X. Wu, D. Chemla-Vogel, C. Tran, S. R. Lee, S. Wong, D. Wilcock, M. L. White, and J. A. Corbin. 2012. A fully human, allosteric monoclonal antibody that activates the insulin receptor and improves glycemic control. Diabetes 61:1263-1271. https://doi.org/10.2337/ db11-1578.

Bjelke, J. R., J. Christensen, S. Branner, N. Wagtmann, C. Olsen, A. B. Kanstrup, and H. B. Rasmussen. 2004. Tyrosine 547 constitutes an essential part of the catalytic mechanism of dipeptidyl peptidase IV. J. Biol. Chem. 279:34691-34697. https://doi.org/10 .1074/jbc.M405400200.

Church, F. C., H. E. Swaisgood, D. H. Porter, and G. L. Catignani. 1983. Spectrophotometric assay using o-phthaldialdehyde for determination of proteolysis in milk and isolated milk proteins1. J. Dairy Sci. 66:1219-1227. https://doi.org/10.3168/jds.S0022 -0302(83)81926-2.

El-Hatmi, H., J.-M. Girardet, J.-L. Gaillard, M. H. Yahyaoui, and H. Attia. 2007. Characterisation of whey proteins of camel (Camelus dromedarius) milk and colostrum. Small Rumin. Res. 70:267-271. https://doi.org/10.1016/j.smallrumres.2006.04.001.

Gaudel, C., A. B. Nongonierma, S. Maher, S. Flynn, M. Krause, B. A. Murray, P. M. Kelly, A. W. Baird, R. J. FitzGerald, and P. Newsholme. 2013. A whey protein hydrolysate promotes insulinotropic activity in a clonal pancreatic $\beta$-cell line and enhances glycemic function in ob/ob mice. J. Nutr. 143:1109-1114. https://doi.org/ 10.3945/jn.113.174912

Gauthier, S. F., Y. Pouliot, and D. Saint-Sauveur. 2006. Immunomodulatory peptides obtained by the enzymatic hydrolysis of whey proteins. Int. Dairy J. 16:1315-1323. https://doi.org/10.1016/j .idairyj.2006.06.014.

Issafras, H., D. H. Bedinger, J. A. Corbin, I. D. Goldfine, V. Bhaskar, M. L. White, P. Rubin, and P. J. Scannon. 2014. Selective allosteric antibodies to the insulin receptor for the treatment of hyperglycemic and hypoglycemic disorders. J. Diabetes Sci. Technol. 8:865-873. https://doi.org/10.1177/1932296814529886.

Jafar, S., H. Kamal, P. Mudgil, H. M. Hassan, and S. Maqsood. 2018. Camel whey protein hydrolysates displayed enhanced cholesteryl esterase and lipase inhibitory, anti-hypertensive and anti-haemolytic properties. Lebensm. Wiss. Technol. 98:212-218. https://doi .org/10.1016/j.lwt.2018.08.024.

Kamal, H., S. Jafar, P. Mudgil, C. Murali, A. Amin, and S. Maqsood. 2018. Inhibitory properties of camel whey protein hydrolysates toward liver cancer cells, dipeptidyl peptidase-IV, and inflammation. J. Dairy Sci. 101:8711-8720. https://doi.org/10.3168/jds 2018-14586.

Lacroix, I. M. E., and E. C. Y. Li-Chan. 2013. Inhibition of dipeptidyl peptidase (DPP)-IV and $\alpha$-glucosidase activities by pepsin-treated whey proteins. J. Agric. Food Chem. 61:7500-7506. https://doi .org/10.1021/jf401000s.

Lambeir, A.-M., C. Durinx, S. Scharpé, and I. De Meester. 2003. Dipeptidyl-peptidase IV from bench to bedside: An update on structural properties, functions, and clinical aspects of the enzyme DPP IV. Crit. Rev. Clin. Lab. Sci. 40:209-294. https://doi.org/10.1080/ 713609354.

Liu, F., G. Baggerman, L. Schoofs, and G. Wets. 2008. The construction of a bioactive peptide database in Metazoa. J. Proteome Res. 7:4119-4131. https://doi.org/10.1021/pr800037n.

Malik, A., A. Al-Senaidy, E. Skrzypczak-Jankun, and J. Jankun. 2012. A study of the anti-diabetic agents of camel milk. Int. J. Mol. Med. 30:585-592. https://doi.org/10.3892/ijmm.2012.1051. 
Maqsood, S., A. Al-Dowaila, P. Mudgil, H. Kamal, B. Jobe, and H. M. Hassan. 2019. Comparative characterization of protein and lipid fractions from camel and cow milk, their functionality, antioxidant and antihypertensive properties upon simulated gastro-intestinal digestion. Food Chem. 279:328-338. https://doi.org/10.1016/j foodchem.2018.12.011

Mati, A., C. Senoussi-Ghezali, S. S. A. Zennia, D. Almi-Sebbane, H. El-Hatmi, and J.-M. Girardet. 2017. Dromedary camel milk proteins, a source of peptides having biological activities - A review. Int. Dairy J. 73:25-37. https://doi.org/10.1016/j.idairyj.2016.12 .001 .

Minkiewicz, P., J. Dziuba, A. Iwaniak, M. Dziuba, and M. Darewicz. 2008. BIOPEP database and other programs for processing bioactive peptide sequences. J. AOAC Int. 91:965-980. https://doi.org/ 10.1093/jaoac/91.4.965.

Mohamad, R. H., Z. K. Zekry, H. A. Al-Mehdar, O. Salama, S. E. ElShaieb, A. A. El-Basmy, M. G. A. M. Al-said, and S. M. Sharawy. 2009. Camel milk as an adjuvant therapy for the treatment of type 1 diabetes: Verification of a traditional ethnomedical practice. J. Med. Food 12:461-465. https://doi.org/10.1089/jmf.2008.0009.

Mudgil, P., B. Baby, Y.-Y. Ngoh, H. Kamal, R. Vijayan, C.-Y. Gan, and S. Maqsood. 2019a. Molecular binding mechanism and identification of novel anti-hypertensive and anti-inflammatory bioactive peptides from camel milk protein hydrolysates. Lebensm. Wiss. Technol. 112:108193. https://doi.org/10.1016/j.lwt.2019.05.091.

Mudgil, P., H. Kamal, G. C. Yuen, and S. Maqsood. 2018. Characterization and identification of novel antidiabetic and anti-obesity peptides from camel milk protein hydrolysates. Food Chem. 259:46-54. https://doi.org/10.1016/j.foodchem.2018.03.082.

Mudgil, P., L. S. Omar, H. Kamal, B. P. Kilari, and S. Maqsood. 2019b. Multi-functional bioactive properties of intact and enzymatically hydrolysed quinoa and amaranth proteins. Lebensm. Wiss. Technol. 110:207-213. https://doi.org/10.1016/j.lwt.2019.04 .084 .

Nabeno, M., F. Akahoshi, H. Kishida, I. Miyaguchi, Y. Tanaka, S. Ishii, and T. Kadowaki. 2013. A comparative study of the binding modes of recently launched dipeptidyl peptidase IV inhibitors in the active site. Biochem. Biophys. Res. Commun. 434:191-196. https://doi.org/10.1016/j.bbrc.2013.03.010.

Nongonierma, A. B., C. Cadamuro, A. Le Gouic, P. Mudgil, S. Maqsood, and R. J. FitzGerald. 2019. Dipeptidyl peptidase IV (DPPIV) inhibitory properties of a camel whey protein enriched hy- drolysate preparation. Food Chem. 279:70-79. https://doi.org/10 .1016/j.foodchem.2018.11.142.

Nongonierma, A. B., and R. J. FitzGerald. 2012. Tryptophan-containing milk protein-derived dipeptides inhibit xanthine oxidase. Peptides 37:263-272. https://doi.org/10.1016/j.peptides.2012.07.030.

Nongonierma, A. B., and R. J. FitzGerald. 2019. Features of dipeptidyl peptidase IV (DPP-IV) inhibitory peptides from dietary proteins. J. Food Biochem. 43:e12451. https://doi.org/10.1111/jfbc.12451.

Nongonierma, A. B., C. Mazzocchi, S. Paolella, and R. J. FitzGerald. 2017. Release of dipeptidyl peptidase IV (DPP-IV) inhibitory peptides from milk protein isolate (MPI) during enzymatic hydrolysis. Food Res. Int. 94:79-89. https://doi.org/10.1016/j.foodres.2017.02 .004 .

Richter, B., E. Bandeira-Echtler, K. Bergerhoff, and C. Lerch. 2008. Dipeptidyl peptidase-4 (DPP-4) inhibitors for type 2 diabetes mellitus. Cochrane Database Syst. Rev. CD006739. https://doi.org/10 .1002/14651858.CD006739.pub2.

Sarah, S. A., W. N. Faradalila, M. S. Salwani, I. Amin, S. A. Karsani, and A. Q. Sazili. 2016. LC-QTOF-MS identification of porcinespecific peptide in heat treated pork identifies candidate markers for meat species determination. Food Chem. 199:157-164. https:/ /doi.org/10.1016/j.foodchem.2015.11.121.

Tagliazucchi, D., S. Martini, S. Shamsia, A. Helal, and A. Conte. 2018. Biological activities and peptidomic profile of in vitro-digested cow, camel, goat and sheep milk. Int. Dairy J. 81:19-27. https:// doi.org/10.1016/j.idairyj.2018.01.014.

Velarde-Salcedo, A. J., A. Barrera-Pacheco, S. Lara-González, G. M. Montero-Morán, A. Díaz-Gois, E. González de Mejia, and A. P. B. De La Rosa. 2013. In vitro inhibition of dipeptidyl peptidase IV by peptides derived from the hydrolysis of amaranth (Amaranthus hypochondriacus L.) proteins. Food Chem. 136:758-764. https:// doi.org/10.1016/j.foodchem.2012.08.032.

\section{ORCIDS}

Abdulrasheed Palakkott $\odot$ https://orcid.org/0000-0002-5958-718X

Chee-Yuen Gan @ https://orcid.org/0000-0002-6509-1068

Sajid Maqsood @ https://orcid.org/0000-0003-2099-8392

Mohammed Akli Ayoub @ https://orcid.org/0000-0003-0022-578X 